\title{
Guest-Mediated Access to a Single DNA Nanostructure from a Library of Multiple Assemblies
}

\author{
Faisal A. Aldaye and Hanadi F. Sleiman*
}

Department of Chemistry, McGill University, 801 Sherbrooke St. West, Montreal, QC, H3A 2K6, Canada

We show that the addition of a small molecule template can result in the quantitative formation of a single DNA nanostructure, using a set of DNA building blocks that otherwise would result in a library of assemblies. Two sequence symmetric DNA structures, in which two identical DNA arms branch from a fully rigid organic vertex, were found to generate a small dynamic library of DNA assemblies composed of cyclic dimer, square and hexameric members. Addition of the guest template $\mathrm{Ru}(\mathrm{bpy})_{3}{ }^{2+}$ provides access to a single member of this library (square 5), and also "funnels" each already formed member into the same single member (i.e. 5). The approach presented here, namely the addition of a small DNAbinding molecule to generate a single nanostructure, will not only be useful for incorporating symmetry for the construction of more complex systems, but also presents the immediate advantage of auto-correcting errors that may form during the initial selfassembly process. We use this method to predictably generate periodic 1-D DNA fibers extending over tens of microns, using two trifunctional symmetrically branched DNA building blocks that otherwise assemble into illdefined oligomeric networks.
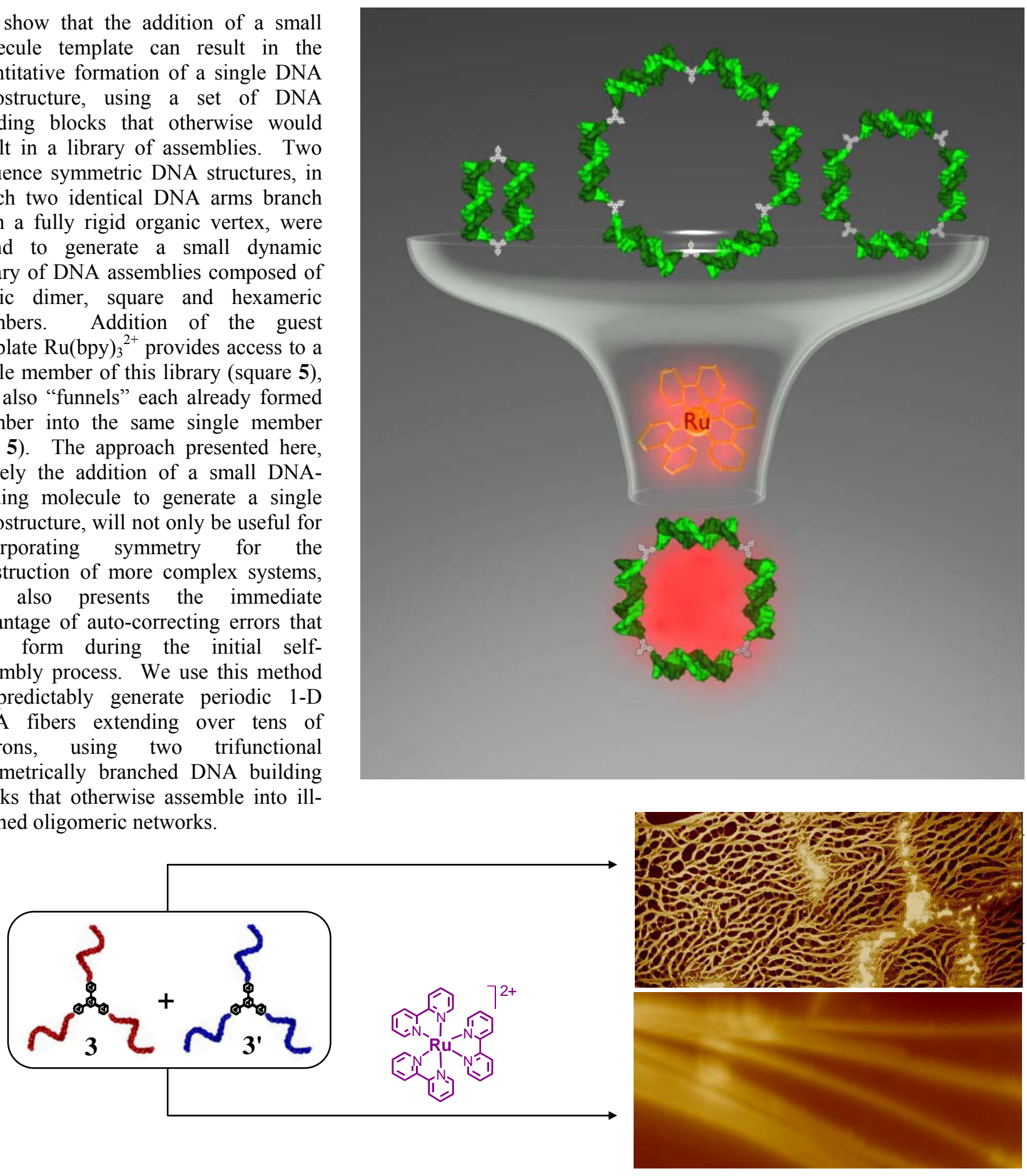


\section{Contents}

$\begin{array}{lll}\text { I. General } & \text { S3 }\end{array}$

$\begin{array}{lll}\text { II. } & \text { Instrumentation } & \text { S3 }\end{array}$

$\begin{array}{ll}\text { III. Synthesis } & \text { S4 }\end{array}$

$\begin{array}{ll}\text { IV. Hybridizations of } 2 \text { to 2' } & \text { S12 }\end{array}$

$\begin{array}{lll}\text { V. } & \text { Enzymatic digestion } & \text { S13 }\end{array}$

VI. Thermocycling of the assemblies generated from 2 and 2' S15

$\begin{array}{ll}\text { VII. Hybridization of } 2 \text { to } \mathbf{2}^{\prime} \text { in presence of } \mathrm{Ru}(\mathrm{bpy})_{3}{ }^{2+} & \mathrm{S} 17\end{array}$

VIII. Time and temperature dependant studies on $\mathbf{4 , 6}$, and oligomers in the presence and absence of $\mathrm{Ru}(\mathrm{bpy})_{3}{ }^{2+} \quad \mathrm{S} 18$

$\begin{array}{lr}\text { IX. Hybridizations of 3 to 3' } & \text { S20 }\end{array}$

$\begin{array}{llr}\text { X. } & \text { AFM sample preparation and analysis } & \text { S29 }\end{array}$

$\begin{array}{llr}\text { XI. References } & \text { S30 }\end{array}$ 


\section{General}

Tris(2,2'-bipyridyl)dichlororuthenium(II) hexahydrate, 1,3,5-tris(4-hydroxyphenyl)benzene $\mathbf{1}$, tris(hydroxymethyl)aminomethane (Tris), boric acid, acetic acid, ethylenediaminetetraacetic acid, $\mathrm{NaCl}$, $\mathrm{MgCl}_{2} 6 \mathrm{H}_{2} \mathrm{O}$, StainsAll ${ }^{\circledR}$, and formamide were used as purchased from Aldrich. Guanidine derivatized $500 \AA$ LCAA-CPG solid support with a loading density of $85 \mu \mathrm{mol} / \mathrm{g}$, guanidine derivatized $1000 \AA$ LCAA-CPG solid support with a loading density of $30 \mu \mathrm{mol} / \mathrm{g}$, guanidine derivatized $2000 \AA$ LCAACPG solid support with a loading density of $5 \mu \mathrm{mol} / \mathrm{g}$, and reagents used for automated DNA synthesis were purchased from ChemGenes. Sephadex G-25 (super fine DNA grade), and Mung Bean Nuclease (source: Mung Bean Sprouts) were purchased from Amersham Biosciences. O’Range Ruler ${ }^{\mathrm{TM}} 20$ base pair molecular weight DNA ladder $(0.1 \mu \mathrm{g} / \mu \mathrm{L})$ was purchased from Fermentas Life Sciences. Microcon ${ }^{\circledR}$ size-exclusion centrifugal filter devices were purchased from Millipore. Ruby Red mica Sheets (1 X 3") for atomic force microscopy (AFM) were purchased from Electron Microscopy Sciences, while etched silicon cantilevers (OMCL-AC160TS) for AFM imaging were used as purchased from Olympus.

\section{Instrumentation}

Standard automated oligonucleotide solid-phase synthesis was performed on a Perspective Biosystems Expedite 8900 DNA synthesizer. UV-vis quantification was conducted on a Varian Cary 300 biospectrophotometer. Gel electrophoresis experiments were carried out on an acrylamide $20 \mathrm{X} 20 \mathrm{~cm}$ vertical Hoefer 600 electrophoresis unit. Temperature cycling experiments were performed on a Flexigene Techne 60 well thermocycler. Electroelution was performed using a Centrilutor $^{\circledR}$ electroeluter from Millipore. ${ }^{1} \mathrm{H}-\mathrm{NMR}$ was obtained using a Mercury $400 \mathrm{MHz}$ NMR spectrometer.

${ }^{13} \mathrm{C}$-NMR was obtained using a Mercury $300 \mathrm{MHz}$ NMR spectrometer. ${ }^{31} \mathrm{P}-\mathrm{NMR}$ spectra were obtained 
using a Gemini $200 \mathrm{MHz}$ NMR spectrometer. High-resolution electrospray ionization mass spectrometry (ESI-MS) measurements were conducted on an IonSpec 7.0 Tesla FTMS instrument (Lake Forest, CA) equipped with a Zspray source from Waters Corporation. Matrix assisted laser desorption time-of-flight mass spectrometry (MALDI-TOF MS) was performed on a KOMPACT MALDI III mass spectrometer. AFM images were either acquired on a Digital Instruments "Dimension 3100" or on an E-scope microscope (Santa Barbara, CA).

\section{Synthesis}

tris-amidite Derivative of 1: The tris-phosphoramidite derivative of 1,3,5-tris(4-hydroxyphenyl)benzene $\mathbf{1}$ was prepared by adapting a procedure reported by Sleiman et al. ${ }^{\mathrm{S} 1}$ Briefly, 1 (50 mg, $\left.0.14 \mathrm{mmol}\right)$ and dimethylaminopyridine $(5 \mathrm{mg}, 0.042 \mathrm{mmol})$ were dried under vacuum for 12 hours. $15.0 \mathrm{~mL}$ of dry THF, diisopropylethylamine $(0.25$ $\mathrm{mL}, 1.4 \mathrm{mmol}$ ) and 2-cyanoethyl diisopropylchlorophosphoramidite

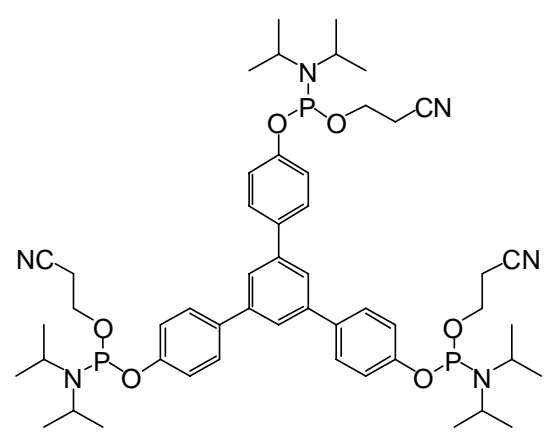
tris-amidite derivative of $\mathbf{1}$ chloride $(0.19 \mathrm{~mL}, 0.84 \mathrm{mmol})$ were added. The mixture was then stirred at room temperature for 30 minutes or until the reaction is complete as monitored by TLC. The THF is removed in vacuo and the yellowish crude precipitate was purified on a silica gel column by elution with dichloromethane:hexanes:triethylamine (30:66:4) $\left(\mathrm{R}_{\mathrm{f}} 0.8\right)$. The tris-phosphoramidite derivative of 1 was obtained as a white solid in 95\% yield. ${ }^{1} \mathrm{H}-\mathrm{NMR}\left(\mathrm{CD}_{2} \mathrm{Cl}_{2}, 400 \mathrm{MHz}\right): \delta 7.71(\mathrm{t}, 3 \mathrm{H}, \mathrm{ArH}, \mathrm{J}=8.0 \mathrm{~Hz}), 7.65$ (t, 6H, ArH, J=8.0Hz), $7.17(\mathrm{t}, 6 \mathrm{H}, \mathrm{ArH}, \mathrm{J}=8.0 \mathrm{~Hz}), 3.95\left(\mathrm{~m}, 6 \mathrm{H}, \mathrm{OCH}_{2}\right), 3.76(\mathrm{~m}, 6 \mathrm{H}, \mathrm{NCH}), 2.70(\mathrm{~m}$, $\left.6 \mathrm{H}, \mathrm{CH}_{2} \mathrm{CN}\right), 1.10-1.30\left(\mathrm{~m}, 36 \mathrm{H}, \mathrm{CH}_{3}\right) \mathrm{ppm} ;{ }^{31} \mathrm{P}-\mathrm{NMR}\left(\mathrm{CD}_{2} \mathrm{Cl}_{2}, 200 \mathrm{MHz}\right): \delta 147.70 \mathrm{ppm} ;{ }^{13} \mathrm{C}-\mathrm{NMR}$ $\left(\mathrm{CD}_{2} \mathrm{Cl}_{2}, 300 \mathrm{MHz}\right): \delta 154.5,141.9,135.6,128.5,124.2,20.5,118.0,59.3,44.0,24.8,24.5,20.7$ ppm; High-Resolution ESI-MS [m/z]: calculated 955.45465, found 955.45642. 
mono- and bis-trityl protected derivatives of 1 : The mono- and bis-trityl protected derivatives of $\mathbf{1}$ were synthesized from the same reaction. Addition of the protecting group trityl chloride to $\mathbf{1}$ results in the statistical generation of a mixture of products that could either contain the tris-, bis-, mono- or un-protected derivatives of vertex 1. The relative amounts of

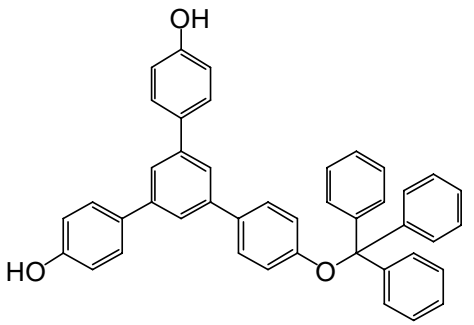
mono-trityl protected derivative of 1 each which is generated depends on the initial ratio of trityl chloride to $\mathbf{1}$ used. A ratio of 1.5:1 was found to provide access to the mono- and bisprotected trityl derivatives in a 1:1 molar ratio, and in an overall yield of $70 \%$. By adapting an earlier procedure reported by Sleiman et al, ${ }^{\mathrm{S} 1} \mathbf{1}(50$ $\mathrm{mg}, 0.14 \mathrm{mmol})$, dimethylaminopyridine $(5.1 \mathrm{mg}, 0.042 \mathrm{mmol})$ and trityl chloride (59 mg, $0.21 \mathrm{mmol}$ ) were initially dissolved in $20 \mathrm{~mL}$ of dry THF. Diisopropylethylamine $(0.25 \mathrm{~mL}, 1.4 \mathrm{mmol})$ is then added dropwise, and

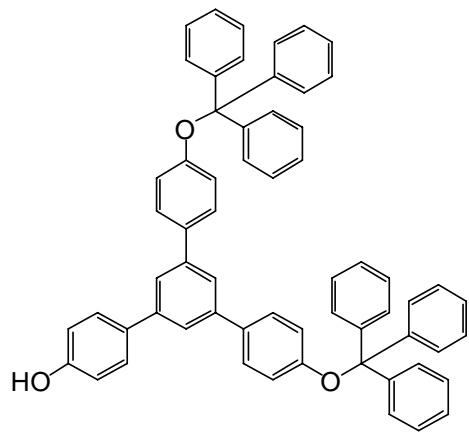

bis-trityl protected derivative of 1 the mixture is allowed to stir under an atmosphere of argon for an additional hour. After the THF is removed in vacuo, the mono- and bis-protected derivatives of $\mathbf{1}$ were isolated and purified from the yellowish crude precipitate on a silica gel column by elution with dichloromethane:triethylamine:methanol (91:4:5) $\left(\mathrm{R}_{\mathrm{f}}\right.$ of the mono-protected derivative is $0.35, \mathrm{R}_{\mathrm{f}}$ of the bis-protected derivative is 0.70 ). The mono-protected derivative of $\mathbf{1}$ was obtained as a white solid in $32 \%$ yield. ${ }^{1} \mathrm{H}-\mathrm{NMR}\left(\mathrm{CD}_{2} \mathrm{Cl}_{2}, 400 \mathrm{MHz}\right): \delta 11.70(\mathrm{~s}, 2 \mathrm{H}, \mathrm{OH}), 7.58(\mathrm{~s}, 1 \mathrm{H}, \mathrm{ArH}), 7.42-7.56(\mathrm{~d}, 8 \mathrm{H}, \mathrm{ArH})$, 7.20-7.40 (m, 15H, TrH), 6.79 (d, 2H, ArH) ppm; ${ }^{13} \mathrm{C}-\mathrm{NMR}\left(\mathrm{CD}_{2} \mathrm{Cl}_{2}, 300 \mathrm{MHz}\right): \delta 157.8,156.1,144.3$, $142.2,141.5,135.4,132.3,129.0,128.2,128.0,127.5,123.4,123.2,121.0,116.2,90.4$ ppm; HighResolution ESI-MS [m/z]: calculated 595.22842, found 595.22677. The bis-protected derivative of 1 was obtained as an off-white solid in $39 \%$ yield. ${ }^{1} \mathrm{H}-\mathrm{NMR}\left(\mathrm{CD}_{2} \mathrm{Cl}_{2}, 400 \mathrm{MHz}\right)$ : $87.42-7.56(\mathrm{~m}, 9 \mathrm{H}$, $\mathrm{ArH})$, 7.22-7.38 (m, 30H, TrH), $6.93(\mathrm{~d}, 2 \mathrm{H}, \mathrm{ArH}), 6.81$ (d, 4H, ArH) ppm; ${ }^{13} \mathrm{C}-\mathrm{NMR}\left(\mathrm{CD}_{2} \mathrm{Cl}_{2}\right.$, 
300MHz): $\delta 156.8,156.2,144.3,141.9 .141 .6,134.1,129.0,128.9,128.0,127.5,127.3,127.1,123.6$, 123.5, 121.0, 115.9, 89.2 ppm; High-Resolution ESI-MS [m/z]: calculated 837.33867, found 837.33742.

bis-amidite mono-trityl protected derivative of 1: The bisamidite mono-trityl protected derivative of $\mathbf{1}$ is synthesized by converting the hydroxyl groups in the previously synthesized mono-trityl protected derivative of $\mathbf{1}$ into amidites. Mono-trityl derivative of $\mathbf{1}(100 \mathrm{mg}, 0.17 \mathrm{mmol})$ and dimethylaminopyridine (0.61 $\mathrm{mg}, 0.051 \mathrm{mmol})$, were dried under vacuum for 12 hours. $15.0 \mathrm{~mL}$ of dry THF, diisopropylethylamine $(0.29 \mathrm{~mL}, 1.7$

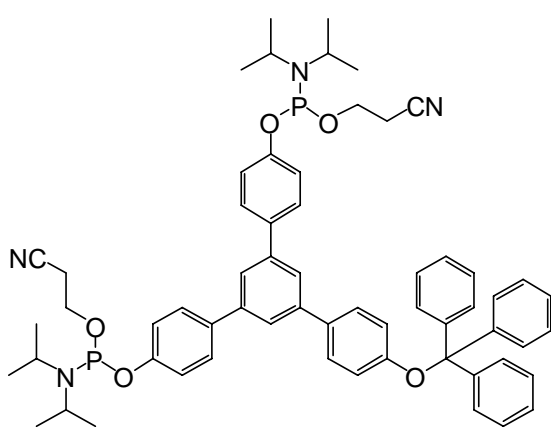

bis-amidite mono-trityl protected derivative of 1 mmol) and 2-cyanoethyl diisopropylchlorophosphoramidite chloride $(0.15 \mathrm{~mL}, 0.68 \mathrm{mmol})$ were added. The mixture was stirred at room temperature for 30 minutes or until the reaction is complete as monitored by TLC. After the THF is removed in vacuo, the yellowish crude precipitate was purified on a silica gel column by elution with dichloromethane:hexanes:triethylamine (40:56:4) $\left(\mathrm{R}_{\mathrm{f}} 0.8\right)$. The bisamidite mono-trityl protected derivative of $\mathbf{1}$ was obtained as an off-white solid in $90 \%$ yield. ${ }^{1} \mathrm{H}-\mathrm{NMR}$ $\left(\mathrm{CD}_{2} \mathrm{Cl}_{2}, 400 \mathrm{MHz}\right):$ 87.46-7.74 (m, 9H, ArH), 7.20-7.40 (m, 15, TrH), 7.15 (d, 4H, ArH, J=8.4Hz), 6.84 (d, $2 \mathrm{H}, \mathrm{ArH}, \mathrm{J}=8.4 \mathrm{~Hz}), 3.68-4.48(\mathrm{~m}, 8 \mathrm{H}, \mathrm{OCH} 2$ and $\mathrm{NCH}), 2.74-2.84\left(\mathrm{~m}, 4 \mathrm{H}, \mathrm{CH}_{2} \mathrm{CN}\right), 1.17-1.47$ [m, 24H, $\left.\mathrm{NCH}\left(\mathrm{CH}_{3}\right)_{2}\right]$ ppm; ${ }^{31} \mathrm{P}-\mathrm{NMR}\left(\mathrm{CD}_{2} \mathrm{Cl}_{2}, 200 \mathrm{MHz}\right)$ : $\delta 147.68 \mathrm{ppm} ;{ }^{13} \mathrm{C}-\mathrm{NMR}\left(\mathrm{CD}_{2} \mathrm{Cl}_{2}, 300 \mathrm{MHz}\right)$ : $\delta 156.2,144.3,141.6,134.0,129.0,128.9,128.4,128.2,128.1,128.0,127.5,127.3,127.1,123.8,120.9$, 120.4, 120.3, 90.4, 59.3, 44.0, 24.6, 24.5, 20.6 ppm; High-Resolution ESI-MS [m/z]: calculated 1039.45939, found 1039.45982 . 
Mono-amidite bis-trityl protected derivative of 1: The monoamidite bis-trityl protected derivative of $\mathbf{1}$ is synthesized by converting the hydroxyl group in the previously synthesized bistrityl protected derivative of $\mathbf{1}$ into an amidite. bis-trityl derivative of 1 (100 mg, $0.12 \mathrm{mmol})$ and dimethylaminopyridine (4.4 $\mathrm{mg}, 0.036 \mathrm{mmol}$ ) were dried under vacuum for 12 hours. $15.0 \mathrm{~mL}$ of dry THF, diisopropylethylamine $(0.21 \mathrm{~mL}, 1.2$

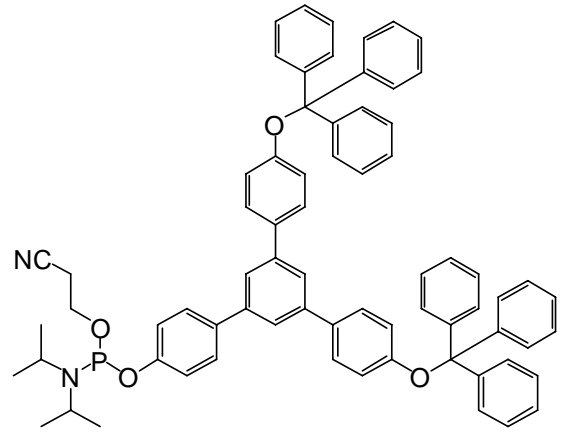

mono-amidite bis-trityl protected derivative of 1 mmol) and 2-cyanoethyl diisopropylchlorophosphoramidite chloride $(0.053 \mathrm{~mL}, 0.24 \mathrm{mmol})$ were added. The mixture was stirred at room temperature for 30 minutes or until the reaction is complete as monitored by TLC. After the THF was removed in vacuo, the yellowish crude precipitate was purified on a silica gel column by elution with dichloromethane:hexanes:triethylamine (40:56:4) $\left(\mathrm{R}_{\mathrm{f}} 0.75\right)$. The mono-amidite bis-trityl derivative of $\mathbf{1}$ was obtained as an off-white solid in $85 \%$ yield. ${ }^{1} \mathrm{H}-\mathrm{NMR}$ $\left(\mathrm{CD}_{2} \mathrm{Cl}_{2}, 400 \mathrm{MHz}\right): \delta 7.40-7.60$ (m, 9H, ArH), 7.13 (d, 2H, ArH, J=7.6Hz), 6.80 (d, 4H, ArH, J=7.6Hz), $3.95\left(\mathrm{~m}, 2 \mathrm{H}, \mathrm{OCH}_{2}\right), 3.78(\mathrm{~m}, 2 \mathrm{H}, \mathrm{NCH}), 2.70\left(\mathrm{t}, 2 \mathrm{H}, \mathrm{CH}_{2} \mathrm{CN}, \mathrm{J}=6.4 \mathrm{~Hz}\right), 1.22-1.27$ [m, $\left.6 \mathrm{H}, \mathrm{CH}_{3}\right] \mathrm{ppm}$; ${ }^{31}$ P-NMR $\left(\mathrm{CD}_{2} \mathrm{Cl}_{2}, 200 \mathrm{MHz}\right): \delta 147.69$ ppm; High-Resolution ESI-MS [m/z]: calculated 997.45982, found 997.45812 .

2, 2', 3 and 3': Three approaches were adopted for accessing building blocks 2, 2', 3, and 3'. The first approach provides access to all three possible DNA conjugated products (i.e. mono-, bis-, and trisbranched derivatives of vertex 1) in relatively lower overall synthetic yields (Scheme S1a), the second provides access to both the bis- and tris- branched conjugated analogues in relatively higher yields (Scheme S1b), while the third provides access to the tris-branched DNA conjugate analogue in an 
essentially quantitative yield (Scheme S1c). Depending on the type and amount of the building blocks being synthesized at the time, all three approaches were used at some point.

Scheme S1 Synthetic approaches to accessing symmetrically branched DNA building blocks.
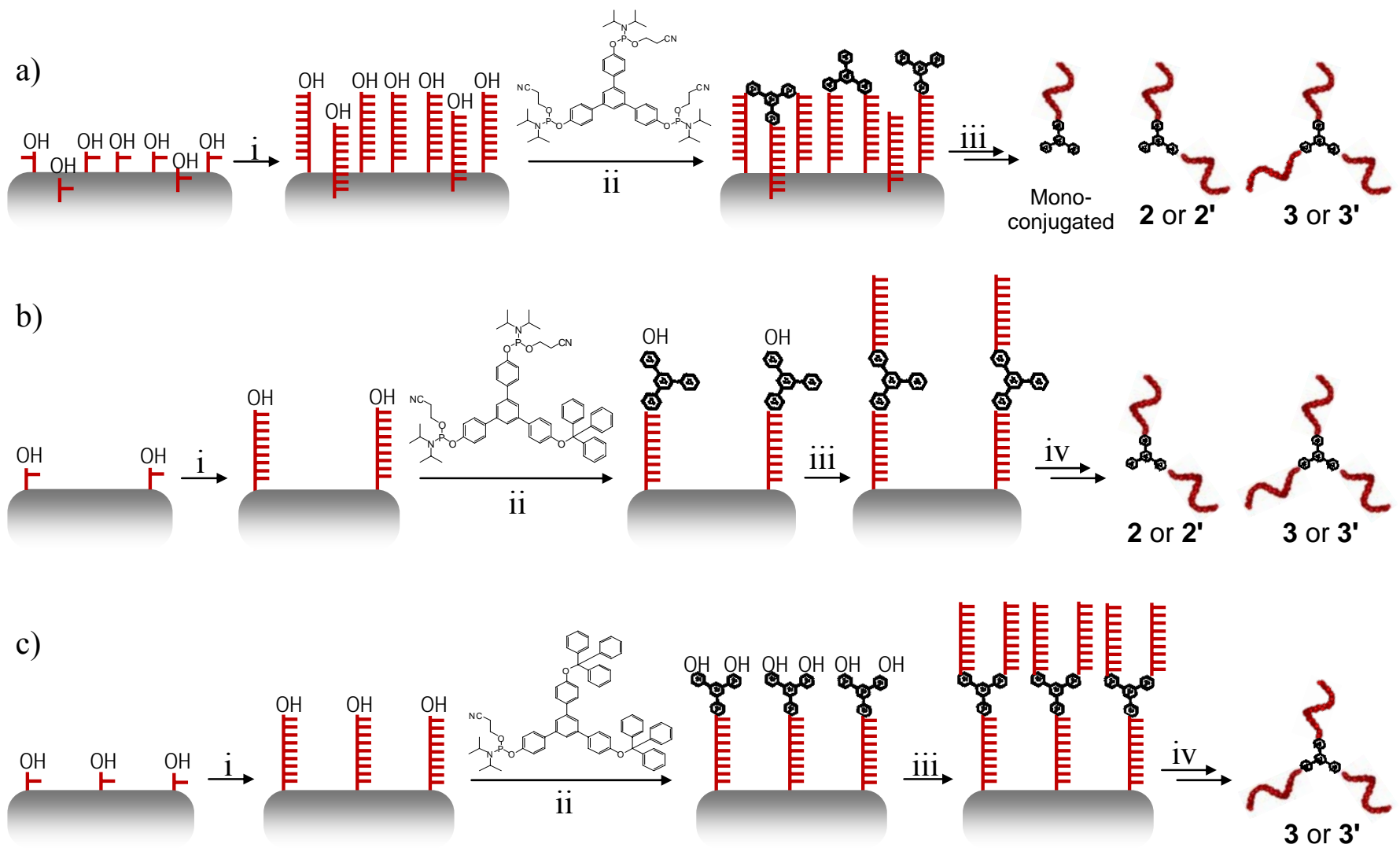

(a) In this approach, (i) DNA of the appropriate sequence is grown on $500 \AA$ functionalized CPG (high loading density; 85 $\mu \mathrm{mol} / \mathrm{g}$ ), followed by (ii) conjugation of the tris-phosphoramidite derivative of vertex 1 to (iii) yield mono-, bis- and trisbranched DNA building blocks (i.e. mono conjugated, 2 or 2', and $\mathbf{3}$ or 3') upon workup and purification. (b) In this approach, (i) DNA is first grown on $2000 \AA$ functionalized CPG (low loading density; $5 \mu \mathrm{mol} / \mathrm{g}$ ), followed by (ii) conjugation of the bis-amidite mono-trityl protected derivative of vertex 1, and the subsequent synthesis of a second DNA arm off of vertex 1 in a $5^{\prime}$ to $3^{\prime}$ direction to (iii) yield bis- and tris-branched DNA building blocks (i.e. 2 or 2', and 3 or 3') upon workup and purification. (c) In this final approach, (i) DNA of the appropriate sequence is grown on $1000 \AA$ functionalized CPG (medium loading density; $35 \mu \mathrm{mol} / \mathrm{g}$ ), followed by (ii) conjugation of the mono-amidite bis-trityl protected derivative of vertex 1, and the subsequent synthesis of two DNA arms off of vertex 1 in a 5' to 3' direction to (iii) yield tris-branched DNA building blocks exclusively (i.e. $\mathbf{3}$ or $\mathbf{3}^{\prime}$ ) upon workup and purification. 
The convergent approach (i.e. first synthetic approach) is attractive because it provides simultaneous access to all three DNA conjugated derivatives of vertex $\mathbf{1}$ (Scheme 1a). In order to properly control the relative ratio of the three building blocks being synthesized, however, it is necessary to carefully choose the loading density of the CPG used and the amount of the tris-amidite derivative of vertex $\mathbf{1}$ added. High loading density CPG insures the possibility of accessing the tris conjugated analogue in reasonable quantities, while a proper ratio of the amidite derivative of the vertex to CPG provides the three conjugated species in the required relative amounts. DNA of the appropriate sequence is first grown on guanidine derivatized $500 \AA$ LCAA-CPG solid support with a loading density of $85 \mu \mathrm{mol} / \mathrm{g}$ using standard automated oligonucleotide synthetic protocols. The tris-amidite derivative of vertex $\mathbf{1}$ is then coupled (amidite:DNA molar ratio of 1.5:1) using a modified protocol with an extended coupling time of 10 minutes. The sequences were cleaved and deprotected in a concentrated solution of $\mathrm{NH}_{4} \mathrm{OH}(12$ hours, $55^{\circ} \mathrm{C}$ ), which was decanted and dried down to yield the crude DNA mixture.

The second synthetic approach involves conjugating the bis-amidite mono-trityl protected derivative of vertex 1 to low loading density CPG, followed by synthesis of a second arm in a $3^{\prime}$ to $5^{\prime}$ direction off of vertex 1 (Scheme 1b). The use of low density CPG provides access to the desired ratio of bis- and tris-branched building blocks. Even though low loading density CPG is used, the tris-conjugated species necessarily forms as a consequence of inter-molecular couplings between CPG beads. DNA of the appropriate sequence is first grown on guanidine derivatized $2000 \AA$ LCAA-CPG solid support with a loading density of $5 \mu \mathrm{mol} / \mathrm{g}$. The bis-amidite mono-trityl protected derivative of vertex $\mathbf{1}$ is then coupled (amidite:DNA molar ratio of 5:1) using a modified protocol with an extended coupling time of 10 minutes. Following deprotection of the trityl group, synthesis is continued off of conjugated vertex $\mathbf{1}$ in a $5^{\prime}$ to $3^{\prime}$ direction using standard reverse-amidite oligonucleotide synthetic methods (extended coupling times of 3 minutes). The sequences were similarly cleaved and deprotected in a concentrated 
solution of $\mathrm{NH}_{4} \mathrm{OH}\left(12\right.$ hours, $\left.55^{\circ} \mathrm{C}\right)$, which was decanted and dried down to yield the crude DNA mixture.

The third approach involves conjugation of the mono-amidite bis-trityl protected derivative of vertex 1 (amidite:DNA molar ratio of 10:1) to medium loading density CPG solid support (1000A, $30 \mu \mathrm{mol} / \mathrm{g}$ ) on which DNA of the appropriate sequence is initially grown in a $3^{\prime}$ to $5^{\prime}$ direction. Following deprotection of both trityl groups, synthesis of two other DNA arms off of conjugated vertex $\mathbf{1}$, in a $5^{\prime}$ to $3^{\prime}$ direction, is then conducted. The use of solid support CPG of medium loading density prevents overcrowding of the DNA strands as each initial DNA strand branches into two. The sequences were then cleaved and deprotected in a concentrated solution of $\mathrm{NH}_{4} \mathrm{OH}\left(12\right.$ hours, $\left.55^{\circ} \mathrm{C}\right)$, which was decanted and dried down to yield the crude DNA mixture.

Purification and characterization of the resulting conjugations (from either of the three synthetic approaches) was conducted as follows. The crude DNA mixtures obtained following cleavage and deprotection from the solid support were purified on $24 \%$ polyacrylamide/7 M urea gels (up to $20 \mathrm{AU}_{260}$ of crude DNA per gel) at a constant current of $10 \mathrm{~mA}$, for 6-7 hours, using $0.09 \mathrm{M}$ Tris-borate-EDTA buffer ( $\mathrm{pH}$ 8.3). Following electrophoresis the plates were wrapped with plastic wrap (Saran Wrap ${ }^{\circledR}$ ) and placed on a fluorescent TLC plate and illuminated with a UV lamp (254 nm). The bands corresponding to the desired products were excised, and the gel pieces were crushed and incubated in 3 $\mathrm{mL}$ of sterile water at $37^{\circ} \mathrm{C}$ (16 hours). The tubes were then vortexed and centrifuged and the supernatants were lyophilized and desalted using Sephadex G-25 size exclusion chromatography. Quantification was carried out by UV-vis analysis, using Beer's law $\left(A_{\text {total }}=A_{\text {vertex }}+A_{D N A}\right)$, in which the extinction coefficient of the vertex at $260 \mathrm{~nm}$ was calculated to be $2.30 \times 10^{5} \mathrm{~L} \mathrm{~mol}^{-1} \mathrm{~cm}^{-1}$.

Matrix assisted laser desorption ionization time-of-flight (MALDI-TOF) mass spectrometry was used to characterize 2, 2', 3 and 3' (along with the mono-conjugated derivatives). MALDI-TOF MS was 
performed using a co-matrix composed of 6-aza-2-thiothymine and fucose, and the additive spermine. The matrix was prepared according to a procedure reported by Allison et al. ${ }^{\mathrm{S} 2}$ The theoretically calculated and the experimentally obtained molecular weights of 2, 2', 3 and 3' (along with the monoconjugated derivatives) are reported in Table S1, along with the 17 base long sequence used (i.e. red sequence) and its complement (i.e. blue sequence).

Table S1 Sequences and molar masses of branched DNA conjugates.

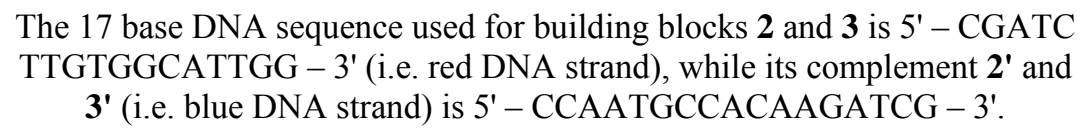

The 17 base DNA sequence used for building blocks 2 and $\mathbf{3}$ is $5^{\prime}-$ CGATC TTGTGGCATTGG - 3' (i.e. red DNA strand), while its complement 2' and 3' (i.e. blue DNA strand) is 5' - CCAATGCCACAAGATCG - 3'.

Calculated / experimentally obtained molar masses

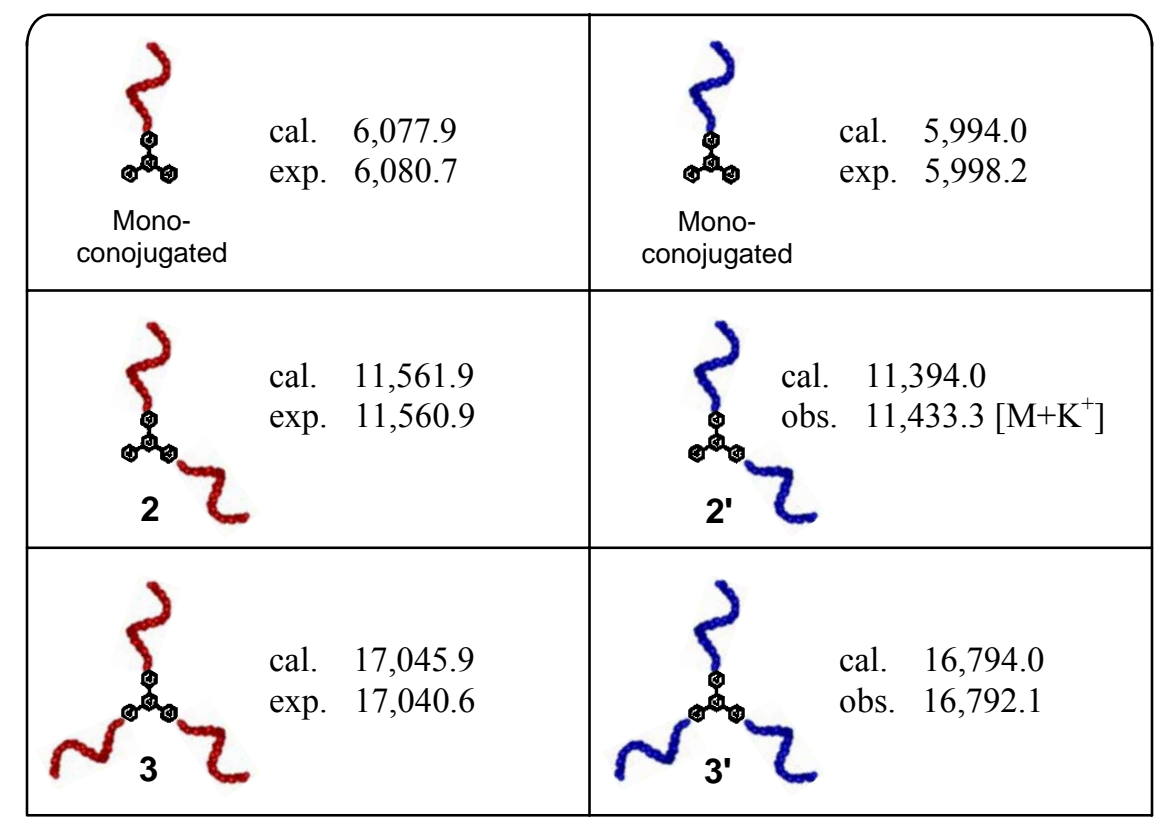

The clean isolation of 2, 2', $\mathbf{3}$ and 3' (along with the mono-conjugated derivatives) was demonstrated using $24 \%$ polyacrylamide/7M urea gels in which the crude mixtures generated from the three synthetic approaches (Figure S1a), and the purified complexes (Figure S1b) were analyzed. The gels were visualized following staining for two hours in a solution of StainsAll ${ }^{\circledR}\left(12.5 \mathrm{mg}\right.$ StainsAll ${ }^{\circledR}$ in $125 \mathrm{~mL}$ of distilled water and $125 \mathrm{~mL}$ of formamide). 
a)

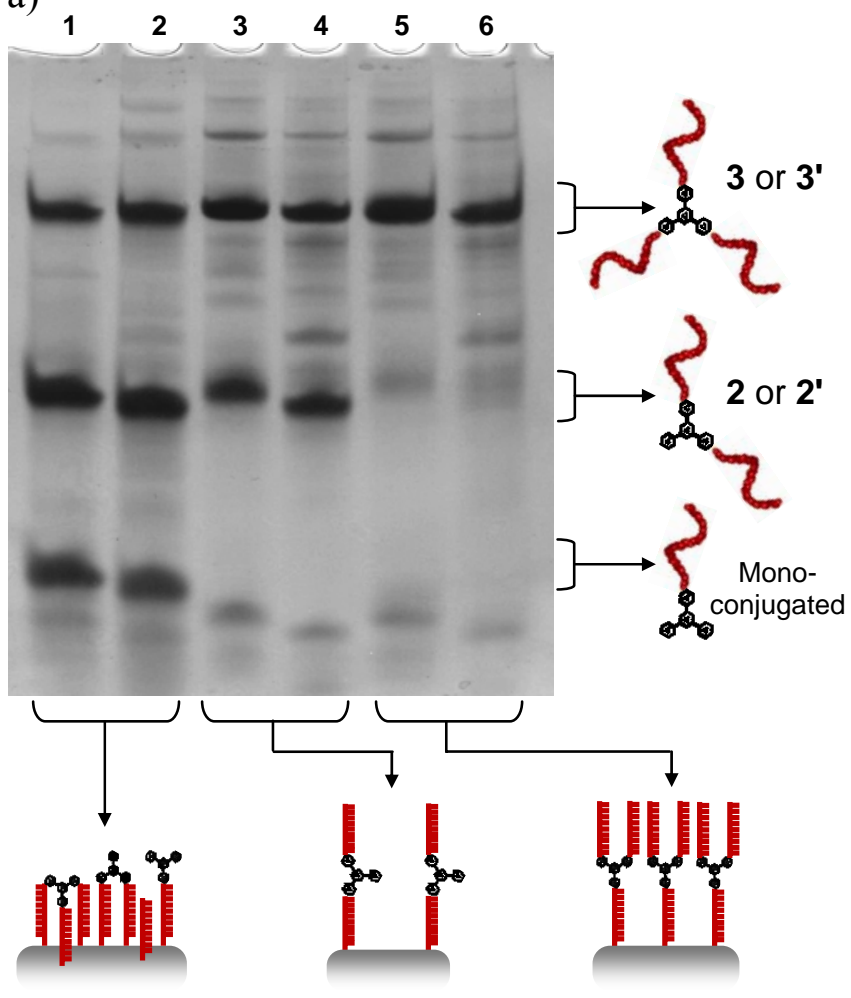

b)

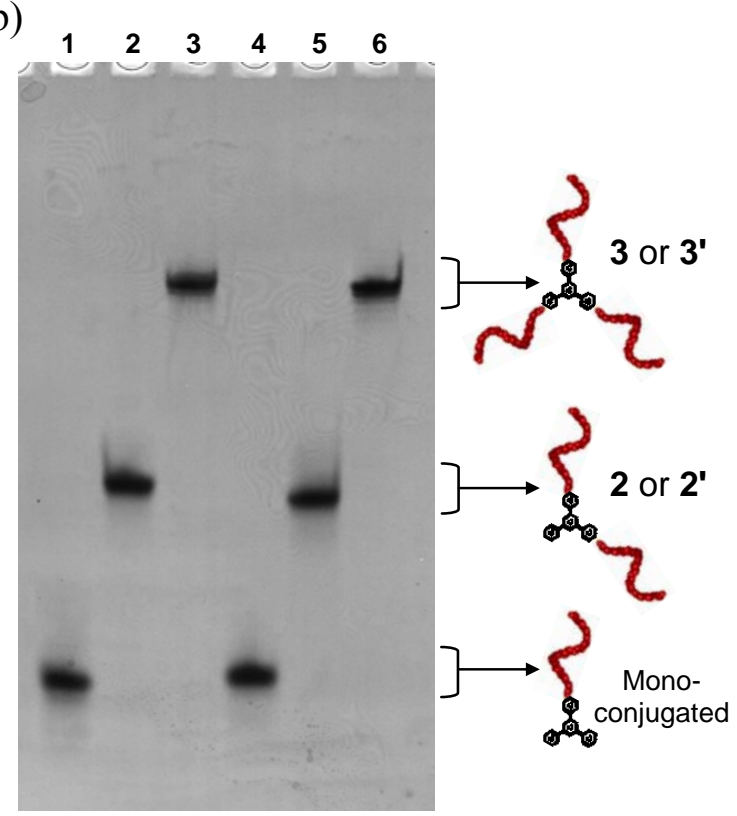

Figure S1 Characterization of 2, 2', 3 and 3'. (a) 24\% denaturing polyacrylamide gel characterizing the branched DNA conjugates generated using the three synthetic approaches. The first approach provides access to all three DNA conjugates (lane 1 for the sequence of the red DNA strand, lane 2 for the sequence of its complementary blue strand), the second synthetic approach provides access to the bis- and tris-conjugates (lanes 3 for the red strand, lane 4 for the blue strand), while the third approach provides exclusive access to the tris-conjugate (lanes 5 for the red strand, lane 6 for the blue strand). (b) Isolated and purified DNA conjugates are characterized using 24\% PAGE. Lanes 1, 2 and 3 correspond to mono-, bis- and tris branched DNA building blocks (red strand), while lanes 4, 5 and 6 correspond to the same set of the complementary conjugates (i.e. blue strand).

\section{Hybridizations of 2 to 2'}

Generally, initial sample preparation involved the drying down of 0.03 ODs of each building block (i.e.

2 and 2' separately), and their subsequent dissolution in $10 \mathrm{uL}$ of TAEmg ${ }^{2+}$ buffer $(40 \mathrm{mM}$ Tris, $20 \mathrm{mM}$ acetic acid, $2 \mathrm{mM}$ EDTA.2Na. $\left.2 \mathrm{H}_{2} \mathrm{O}, 12.5 \mathrm{mM} \mathrm{MgCl}_{2} \cdot 6 \mathrm{H}_{2} 0\right)$. The two solutions, each containing one of the two building blocks, were then hybridized to each other using one of the following four hybridization protocols: 1) incubation at $0^{\circ} \mathrm{C}$ for 15 minutes followed by mixing and incubation at $0^{\circ} \mathrm{C}$ for an additional 15 minutes, 2) incubation at $25^{\circ} \mathrm{C}$ for 15 minutes followed by mixing and incubation at 
$25^{\circ} \mathrm{C}$ for an additional 15 minutes, 3) incubation at $95^{\circ} \mathrm{C}$ for 2 minutes followed by mixing and incubation at $0^{\circ} \mathrm{C}$ for an additional 15 minutes, or 4) incubation at $55^{\circ} \mathrm{C}$ for 10 minutes followed by mixing and incubation at $55^{\circ} \mathrm{C}$ for an additional 16 hours. Analysis of the resulting structures was performed using a $10 \%$ native polyacrylamide gel, run at a constant current of $10 \mathrm{~mA}\left(4^{\circ} \mathrm{C}, 17\right.$ hours).

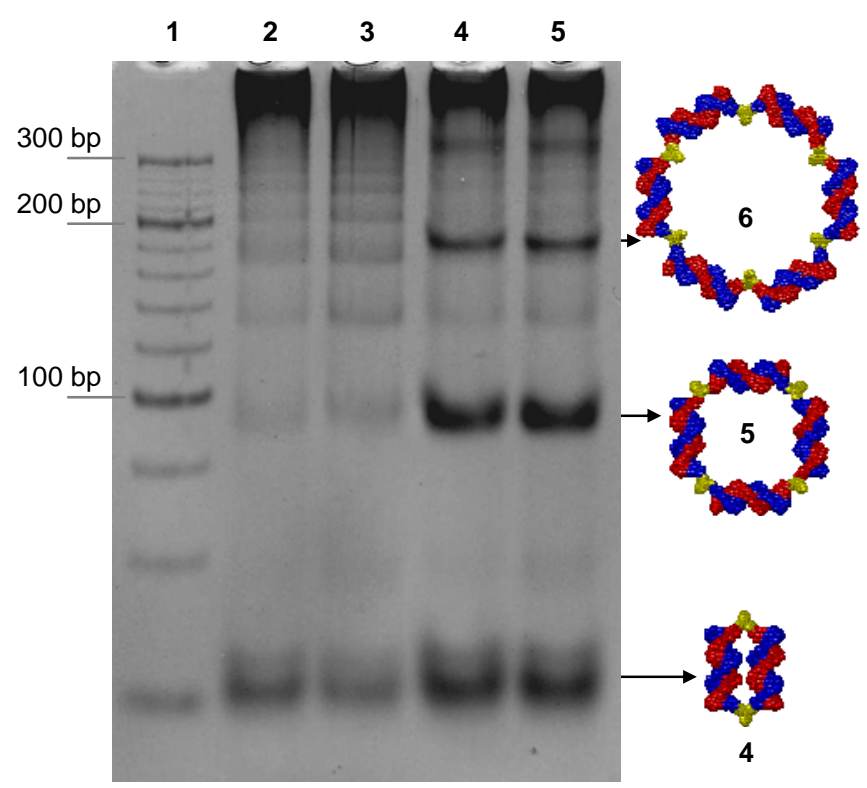

As seen in Figure S2, hybridization protocols 1 and 2 result in a single major product of relatively little-to-no electrophoretic mobility

Figure S2 Hybridization of 2 to 2'. Self-assembly of 2 with $2^{\prime}$, by their simple addition at $0^{\circ} \mathrm{C}$ (lane 2), addition at $25^{\circ} \mathrm{C}$ (lane 3), addition at $95^{\circ} \mathrm{C}$ followed by incubation at $0^{\circ} \mathrm{C}$ for 30 minutes (lane 4), and addition at $55^{\circ} \mathrm{C}$ followed by incubation at $55^{\circ} \mathrm{C}$ for 16 hours (lane 5). Lane 1 contains the 20 base pair linear molecular weight DNA ladder.

(lanes 2 and 3 respectively). These bands have been assigned to large oligomeric assemblies generated from 2 and 2'. Hybridization protocols 3 and 4, on the other hand, also generate a small library of discrete assemblies of relatively faster electrophoretic mobility (lanes 4 and 5, respectively). The three major discrete assemblies 4, 5, and 6 are found to move as a 40-, 90- and a 180-mer, when compared to the 20 base pair linear DNA ladder in lane 1 of the same figure, and have since been assigned to dimeric, tetrameric and hexameric cyclic assemblies generated from 2, 4 and 6 bis-branched building blocks.

\section{Enzymatic digestion}

The cyclic nature of 2, 4, and $\mathbf{6}$ has been ascertained using Mung Bean nuclease (MBN) digestion assays. Under optimized conditions, this enzyme is selective for the digestion of single stranded DNA over that of double stranded DNA by a factor of $30,000: 1 .^{\mathrm{S} 3} \mathrm{MBN}$ is thus expected to degrade linear 


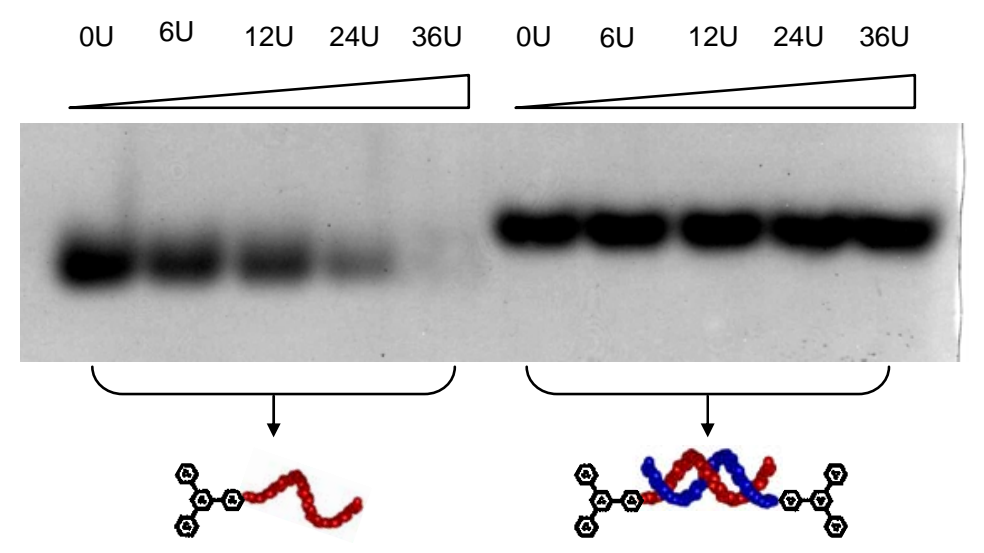

Figure S3 Protocol for the selective digestion of singlestranded DNA. Enzymatic digestion study determining that the use of $36 \mathrm{U}$ of $\mathrm{MBN}$, at $0^{\circ} \mathrm{C}$ and $3 \mathrm{hrs}$, is selective for single strand digestion.

open structures that contain single stranded DNA, but is not expected to degrade cyclic closed structures containing only double stranded DNA. In an attempt to ensure that the enzyme is active on DNA to which our vertex is attached and to find the optimal conditions under which single stranded DNA is preferentially digested, initial work was directed towards subjecting the double and single stranded version of the mono-conjugated building blocks to varying amounts of the enzyme. Digestions are performed in an ice bath for a period of 3 hours. In all these cases, $1.2 \times 10^{-10}$ moles of either double stranded or single stranded mono-conjugated building blocks, in $10 \mu \mathrm{L}$ of TAEmg ${ }^{2+}$ buffer, were subjected to 6,12, 24 and 36 units of enzyme. The addition of 36 units of MBN results in the selective and complete digestion of the single stranded species with very little effect to the double stranded analogue (Figure S3). As seen in Figure S4, treatment of the self-assembled mixture resulting from the hybridization of 2 to $2^{\prime}$ using protocol 3 (i.e. incubation of each building block at $95^{\circ} \mathrm{C}$ for 2 minutes followed by mixing and incubation at $0^{\circ} \mathrm{C}$ for an additional 15 minutes) results in no shift in band mobility for either structures 4,5 , or 6 . 


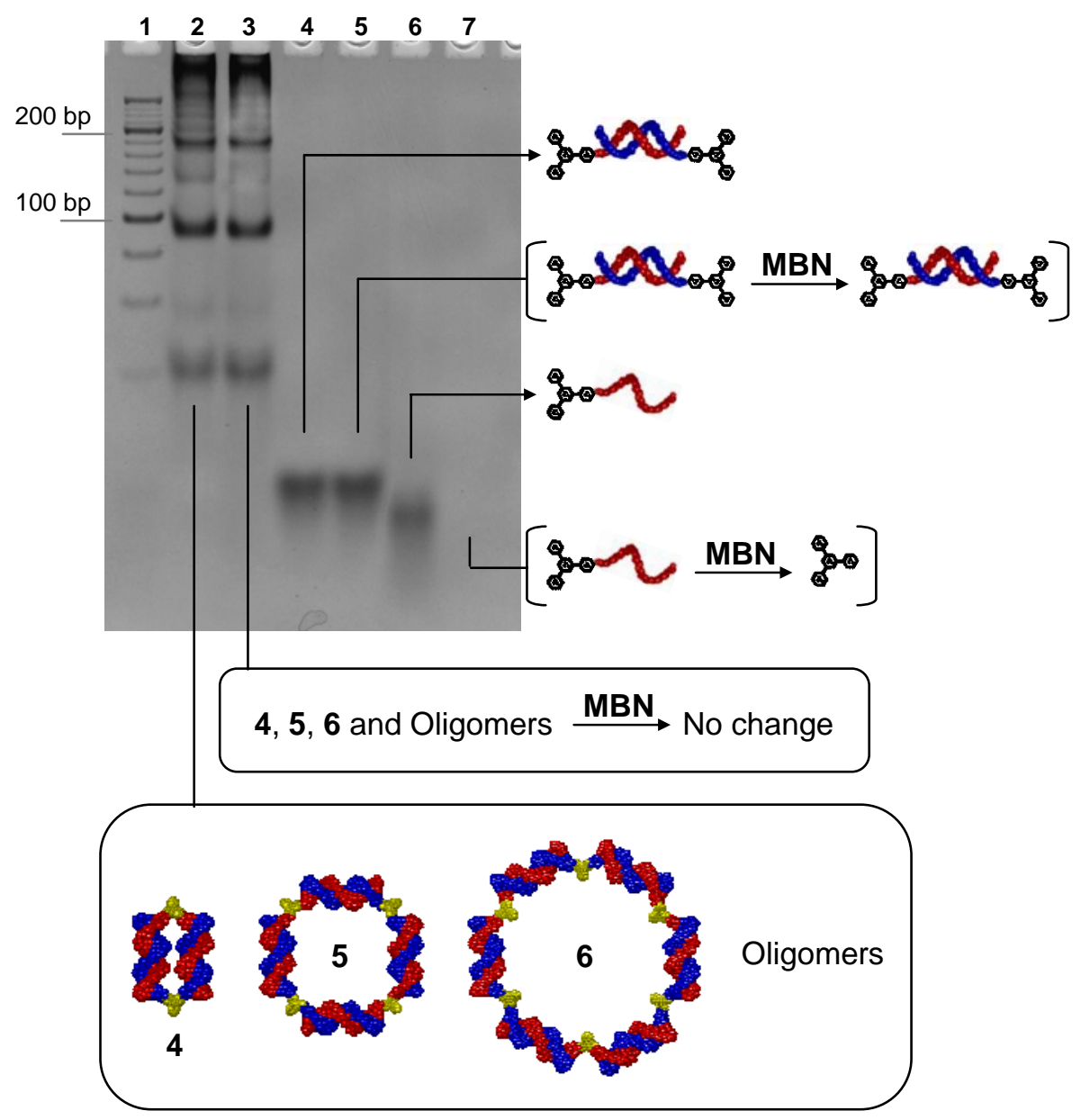

Figure S4 Enzymatic digestion of the assemblies generated from 2 and 2'. MBN enzymatic digestion confirms the double stranded cyclic nature of discrete assemblies 4, 5 and $\mathbf{6}$. Lanes 2 and 3 contain the self-assembled library generated using 2 and 2' before and after treatment with $\mathrm{MBN}$, respectively, while lanes 4 and 5 contain the single-stranded mono-conjugated building block before and after treatment with MBN, respectively. Lane 1 contains the 20 base pair linear molecular weight DNA ladder.

\section{Thermocycling of the assemblies generated from 2 and 2'}

In an attempt to better understand the stability of the assemblies generated from $\mathbf{2}$ and $\mathbf{2}$, thermocycling experiment were conducted. In a first experiment, the mixture generated from the hybridization of building blocks 2 and 2' using hybridization protocol 3 (i.e. 4, 5, 6, and oligomers) was thermocycled between $5^{\circ} \mathrm{C}$ and $90^{\circ} \mathrm{C}$ a total of $1,5,25$, and 66 times. As seen in Figure S5a, analysis using $10 \%$ native polyacrylamide gel electrophoresis revealed the gradual decrease in the relative amount of the 
oligomers remaining in the mixtures (lanes $2,3,5$, for 1,5 , and 25 cycles, respectively), and their essential elimination following 66 such thermocycles (lane 5). This indicates that the oligomeric species are kinetic products, while the discrete assemblies are thermodynamically stable.

In a second experiment, the discrete members generated from the same self-assembled library (i.e. dimer 4 , tetramer $\mathbf{5}$, or hexamer 6 ) were each isolated and subjected to a similar thermocycling study in which each isolated species was cycled between $5^{\circ} \mathrm{C}$ and $90^{\circ} \mathrm{C}$ a total of 66 times. Isolation of each assembly was conduction using electroelution with a Centrilutor ${ }^{\circledR}$ electroeluter from Millipore. As seen in Figure S5b, subjecting dimer 4, tetramer 5, or hexamer $\mathbf{6}$ to such a thermocycling experiment results in the re-generation of the same initial library containing $4,5,6$, and oligomers, indicating that the individual discrete members generated in this library are in fact dynamic in behavior.
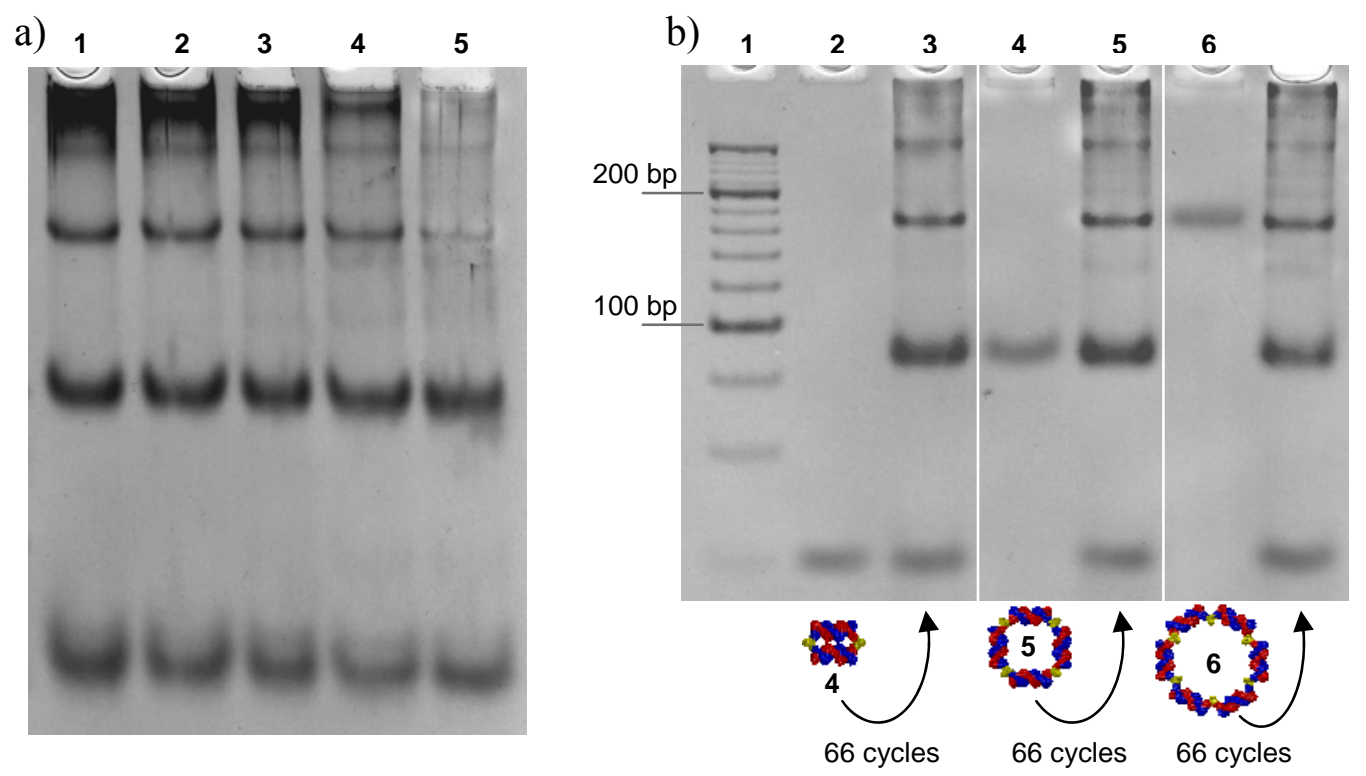

Figure S5 Thermocycling of the structures generated from 2 and 2'. (a) The self-assembled mixture generated from the hybridization of 2 to $2^{\prime}$ (addition at $95^{\circ} \mathrm{C}$, followed by incubation at $0^{\circ} \mathrm{C}$ for 30 minutes) (lane 1) was cycled between 90 and $20^{\circ} \mathrm{C}$ a total of $1,5,25$ and 55 times (lanes 2, 3, 4 and 5, respectively). (b) Isolated dimer 4 (lane 2), tetramer 5 (lane 4) and hexamer 6 (lane 6) were cycled between 90 and $20^{\circ} \mathrm{C} 66$ times (lanes 3, 5, and 7, respectively). Lane 1 contains the 20 base pair linear molecular weight DNA ladder. 


\section{Hybridization of 2 to 2 ' in presence of $R u(b p y)_{3}{ }^{2+}$}

Although the assembly of 2 to $2^{\prime}$ using hybridization protocol 2 (i.e. incubation at $25^{\circ} \mathrm{C}$ for 15 minutes followed by mixing and incubation at $25^{\circ} \mathrm{C}$ for an additional 15 minutes) generates oligomers, the same hybridization in the presence of the small molecule $\mathrm{Ru}(\mathrm{bpy})_{3}{ }^{2+}$ results in tetramer 5 quantitatively. See Figure $2 b$ in manuscript. Generally, hybridizations in the presence of $\mathrm{Ru}(\mathrm{bpy})_{3}{ }^{2+}$ are performed following the addition of $4 \mu \mathrm{L}$ of a $\mathrm{Ru}(\mathrm{bpy}){ }_{3}{ }^{2+}$ solution (10 $\mathrm{mM}$ in water) to building block $2^{\prime}$, and the subsequent hybridization of this solution to 2 as per the specified hybridization protocol.

$\mathrm{Ru}(\mathrm{bpy})_{3}{ }^{2+}$ is a weak electrostatic binder of DNA. In an attempt to elucidate the specificity of this molecule in mediating the formation of tetramer 5 over the other members of the library generated from 2 and 2', AMBER force-field modeling studies (HyperChem) were conducted on dimer 4, tetramer 5 and hexamer $\mathbf{6}$, in the presence and absence of the small molecule Ru(bpy) ${ }_{3}{ }^{2+}$ (Figure S6). Dimer 4 was found to generate a relatively small cavity that is incapable of comfortably accommodating any
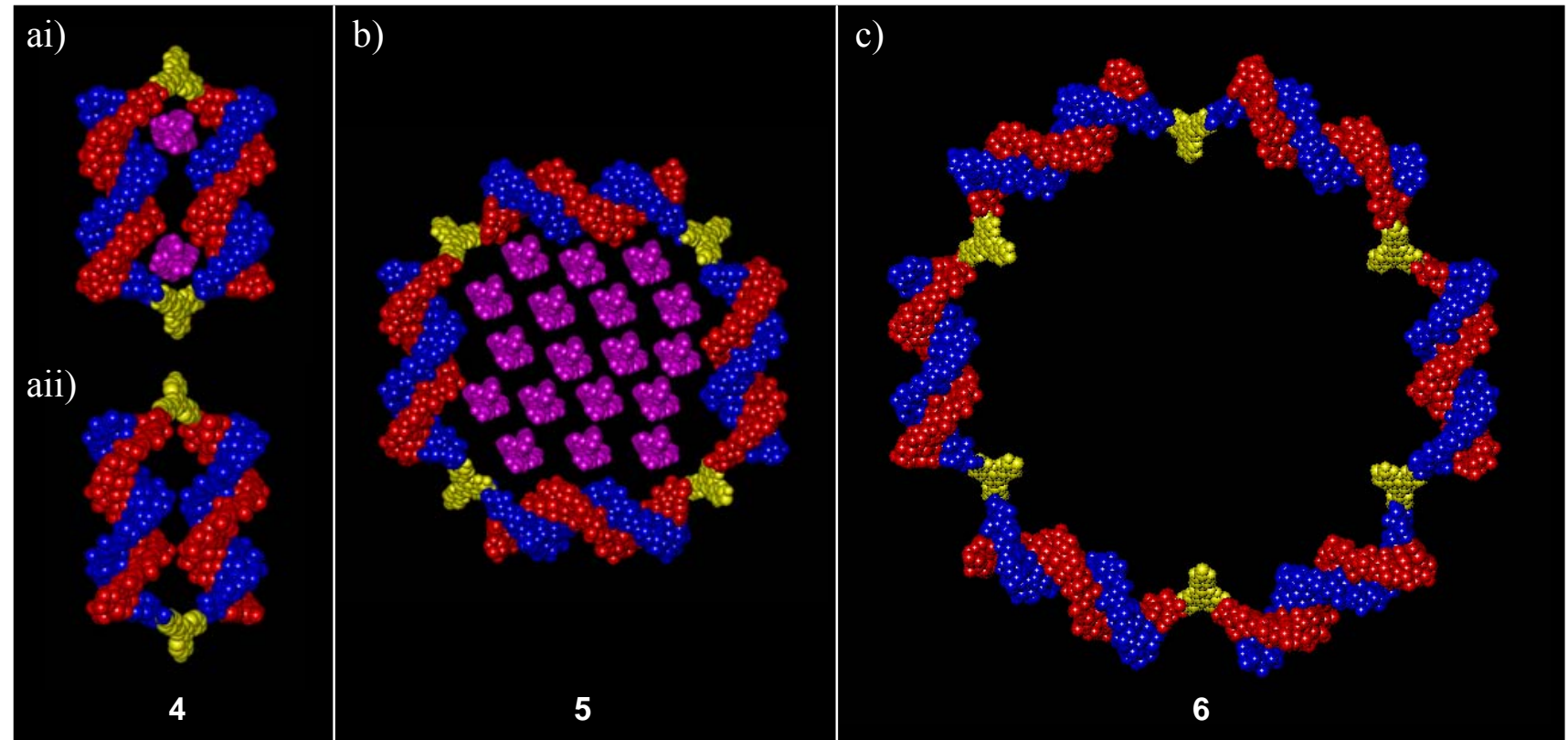

Figure S6 HyperChem modeling of 4, 5 and 6. Simple HyperChem modeling of the cavities generated from 4, 5 and 6 reveal that (ai) dimer 4 is barely capable of packing two Ru(bpy) ${ }_{3}{ }^{2+}$ molecules (shown in purple), (aii) if any at all, while (b) tetramer 5 possesses a cavity big enough to pack at least 18 ruthenium molecules. (c) Hexamer $\mathbf{6}$ is found to generate and an even bigger cavity, when compared to either dimer 4 or tetramer 5. 
significant number of ruthenium molecules (Figure S6ai), and therefore, its templated generation is not expected to occur as a consequence of the $\mathrm{Ru}(\mathrm{bpy})_{3}{ }^{2+}$ molecules. Note that depending on the starting point, minimization of dimer $\mathbf{4}$ could also result in an assembly that is not capable of encapsulating any $\mathrm{Ru}(\mathrm{bpy})_{3}{ }^{2+}$ molecules (Figure S6aii). Tetramer 5, and hexamer $\mathbf{6}$ were found to contain cavities large enough to accommodate a number of such ruthenium molecules (Figure S6aiii-iv), and so, either of them possess the potential to be directly templated by $\mathrm{Ru}(\mathrm{bpy})_{3}{ }^{2+}$. This would explain why this small molecule template biases the library against formation of dimer 4 .

But why does the ruthenium template bias the library exclusively in favor of square 5 , rather than hexamer 6? In earlier studies, we had noticed that square 5 may be slightly more thermodynamically favored over hexamer 6, as repeated heating and cooling cycles (without the template) show the enrichment of this member and reduction in the amount of hexamer formed. It is possible that binding to $\mathrm{Ru}(\mathrm{bpy})_{3}{ }^{2+}$ further increases the difference in stability between the square and hexamer. We also found that the ruthenium template accelerates the equilibration process itself. Therefore, the $\mathrm{Ru}(\mathrm{bpy})_{3}{ }^{2+}$ template likely biases the library against formation of dimer 2 , and also possibly accelerates the formation of DNA square 5 over the less stable hexamer 6 .

\section{Time and temperature dependent studies on 4, 6, and oligomers in the presence and absence of $\operatorname{Ru}(\mathrm{bpy})_{3}{ }^{2+}$}

In an attempt to better understand the behavior of the library members in response to the small molecule $\mathrm{Ru}(\mathrm{bpy})_{3}{ }^{2+}$, time and temperature dependant experiments in the presence and absence of $\mathrm{Ru}(\mathrm{bpy})_{3}{ }^{2+}$ were conducted on dimer 4, hexamer $\mathbf{6}$ and oligomers. In a first experiment, isolated 4, 6 or oligomers were left incubating at either $25^{\circ} \mathrm{C}$ or $55^{\circ} \mathrm{C}$ for a period of 16 hours, while in a second experiment, isolated 4, 6, and oligomers were subjected to the same test (i.e. incubation at either $25^{\circ} \mathrm{C}$ or $55^{\circ} \mathrm{C}$ for 16 
hours) but in the presence of the small molecule $\mathrm{Ru}(\mathrm{bpy})_{3}{ }^{2+}$. As seen in Figure S7, subjecting either 4, 6, or oligomers (lanes 1,4 , and 7) to incubation at $25^{\circ} \mathrm{C}$ for 16 hours results in a relative increase in the amount of oligomers observed for 4 and 6 (lanes 5 and 8, respectively) and no detectable change for the oligomers (lane 2). Incubation of the same set of species at $55^{\circ} \mathrm{C}$, however, results in re-equilibration into the initial library of assemblies (i.e. 4, 5, 6, and oligomers) for each of $\mathbf{4}, \mathbf{6}$, and oligomers (lanes 3 , 6 , and 9 , respectively).

The observed behavior is quite different in the presence of the small molecule $R u(b p y)_{3}{ }^{2+}$. When left incubating at $25^{\circ} \mathrm{C}$ for 16 hours with $\mathrm{Ru}(\mathrm{bpy})_{3}{ }^{2+}, \mathbf{4 ,} \mathbf{6}$ and oligomers re-equilibrate into the initial set of assemblies 4, 5, 6, and oligomers (Figure 1c; manuscript). While incubation at $55^{\circ} \mathrm{C}$ for 16 hours, also with $\mathrm{Ru}(\mathrm{bpy})_{3}{ }^{2+}$, results in re-equilibration of either 4,6 , or oligomers into tetramer 5 quantitatively. $\mathrm{Ru}(\mathrm{bpy})_{3}{ }^{2+}$ essentially has the capacity to inter-convert the members of the library generated from $\mathbf{2}$ and $\mathbf{2}$ into tetramer $\mathbf{5}$. The ability of $\mathrm{Ru}(\mathrm{bpy})_{3}{ }^{2+}$ to provide access to a single structure from sequence degenerate building blocks will allow for the incorporation of symmetry into more complex systems, while its ability to funnel other members of the library into the same single assembly provides a built in mechanism correcting for errors generated during the initial assembly process.

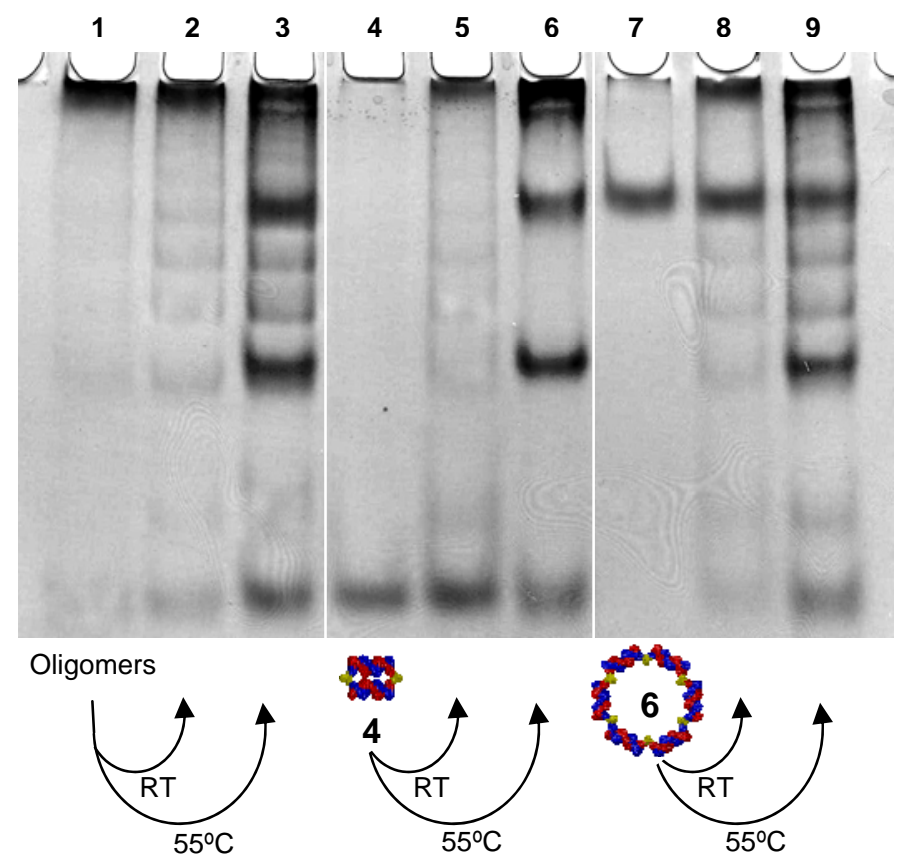

Figure S7 Dynamic character of the assemblies generated from 2 and 2'. The oligomers generated using 2 and 2' (lane 1) were incubated at $25^{\circ} \mathrm{C}$ and $55^{\circ} \mathrm{C}$ for 16 hours (lanes 2 and 3 , respectively). While, isolated tetramer 4 (lane 4) and hexamer 6 (lane 7) were also incubated at $25^{\circ} \mathrm{C}$ and $55^{\circ} \mathrm{C}$ for 16 hours (lanes 2 and 3 for $\mathbf{4}$; lanes 8 and 9 for $\mathbf{6}$, respectively). 


\section{Hybridizations of 3 to 3 '}

Based on the observed self-assembly behavior of 2 to 2 ', the selfassembly of the tris-conjugated analogous 3 and 3 ' is expected to result in high molecular weight networks that would possess little-tono electrophoretic mobility on gel electrophoresis. As seen in Figure

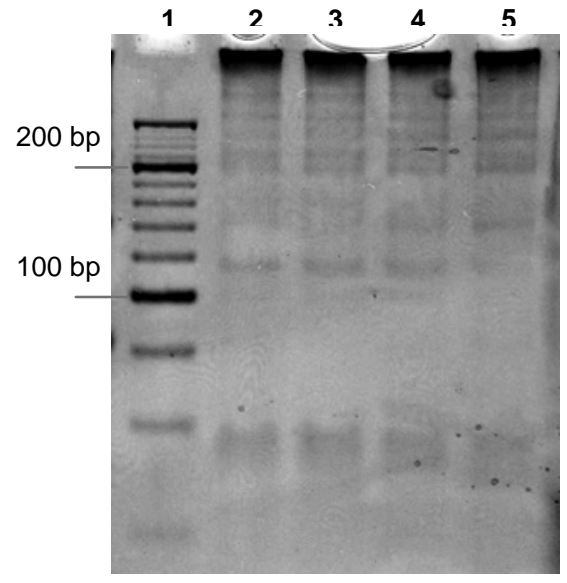

Figure S8 Self-assembly of 3 and 3 '. $10 \%$ native gel analysis of the products generated from 3 and $3^{\prime}$ at $0^{\circ} \mathrm{C}$ (lane 2$), 25^{\circ} \mathrm{C}$ (lane 3 ), $95^{\circ} \mathrm{C}$ followed by $0^{\circ} \mathrm{C}$ for 30 minutes (lane 4), and $55^{\circ} \mathrm{C}$ followed by $55^{\circ} \mathrm{C}$ for 16 hours (lane 5). Lane 1 contains a 20 base pair DNA ladder. expected to be ill-defined in composition. This was in fact confirmed using atomic force microscopy experiments in which the extended DNA networks generated from the assembly of $\mathbf{3}$ to $\mathbf{3}^{\prime}$ are imaged and analyzed (Figure S9). In order to confirm that these networks are not a consequence of the self-assembly of either $\mathbf{3}$ to itself, or of $\mathbf{3}^{\prime}$ to itself, control experiments were conducted in which 0.03 ODs of 3 and of 3' were also individually analyzed using AFM. As seen in Figure S10, neither 3 nor 3' generate any observable higher ordered constructs, and certainly not the extended networks observed in Figure S9. 
a)

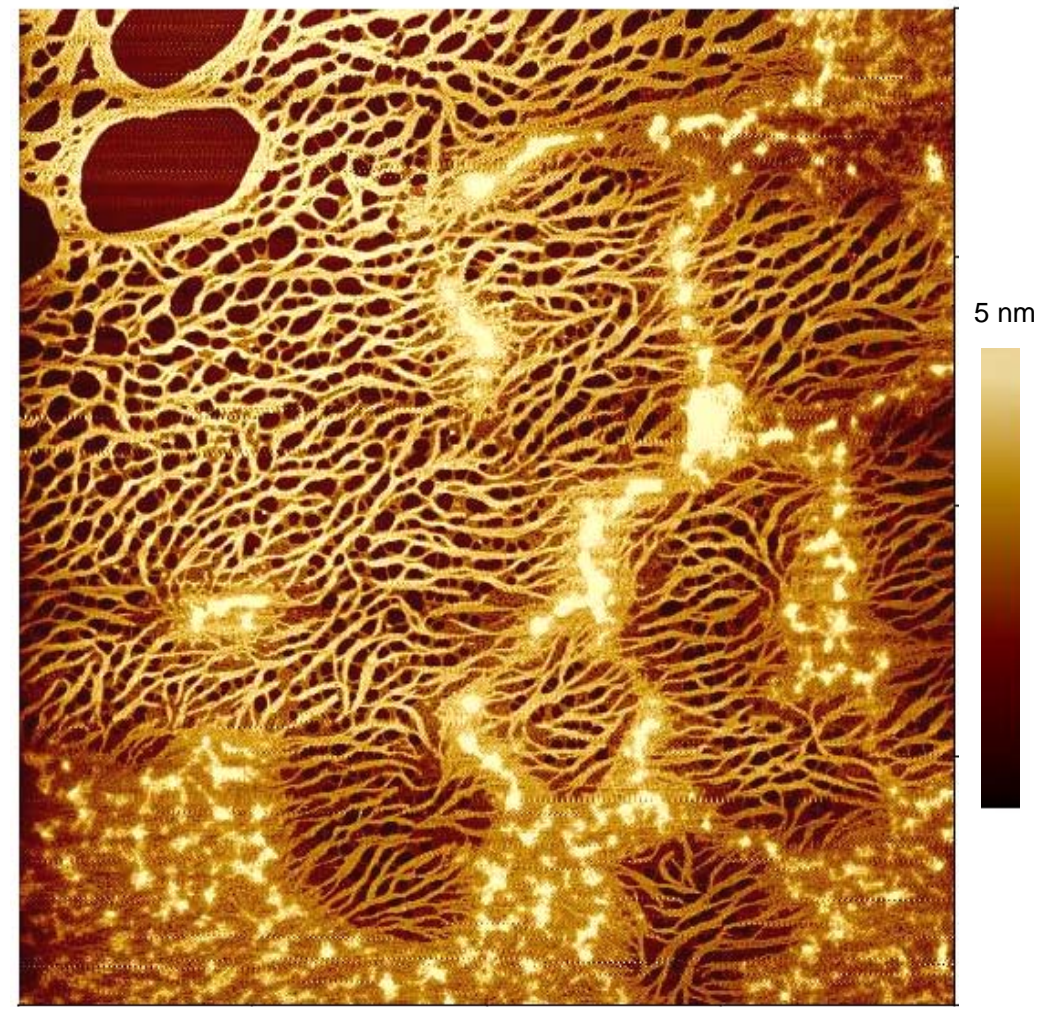

$10 \mu \mathrm{m}$ b)

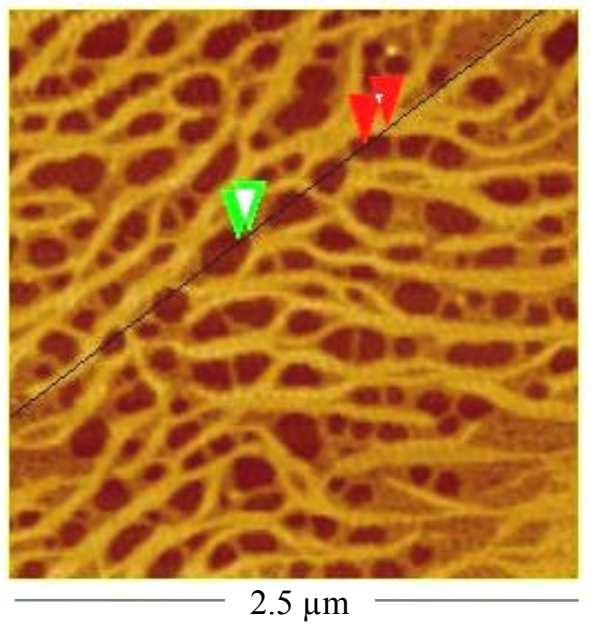

ํำ

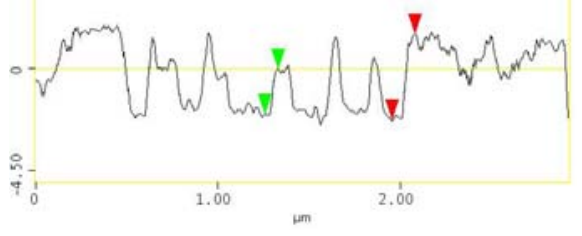

vert distance $\quad 3.782 \mathrm{~nm}$

vert distance $\quad 1.973 \mathrm{~nm}$

Figure S9 AFM analysis of $\mathbf{3}$ and 3'. (a) AFM analysis of the structures generated from the self-assembly of $\mathbf{3}$ and $\mathbf{3}$ reveal the formation of ill-defined oligomeric networks. (b) Further cross-sectional analysis of these networks reveal assemblies with a step-height of $\sim 2 \mathrm{~nm}$ (i.e. diameter of double stranded DNA).

a)

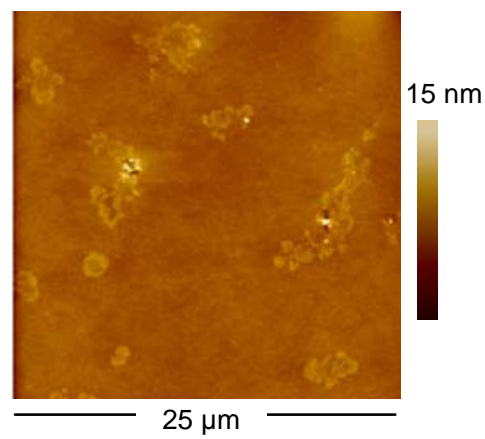

b)

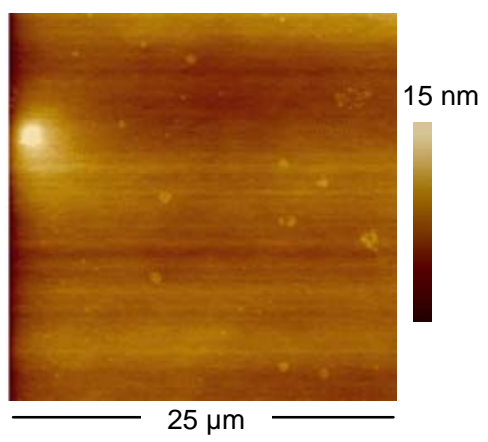

Figure S10 Control experiments on 3 and 3'. No assemblies of any type were observed when either of $\mathbf{3}$ (panel a) or 3' (panel b) are individually analyzed using AFM 
In the presence of the structure selective small molecule $\mathrm{Ru}(\mathrm{bpy})_{3}{ }^{2+}$, the self-assembly of $\mathbf{3}$ to $\mathbf{3}^{\prime}$ is expected to generate ordered periodic networks. This is a direct consequence of the observed ability of $\mathrm{Ru}(\mathrm{bpy})_{3}{ }^{2+}$ to template the selective access to tetramer $\mathbf{5}$ from $\mathbf{2}$ and $\mathbf{2}^{\prime}$. In a manner analogous to that of 2 and 2' (Scheme S1a; manuscript), the assembly of $\mathbf{3}$ to $\mathbf{3}^{\prime}$ with $\mathrm{Ru}(\mathrm{bpy}){ }_{3}{ }^{2+}$ is also expected to initially result in the formation of a tetrameric construct (Scheme S2i). However, unlike tetramer 5, the square generated from 3 and 3' (i.e. tetramer 7) also contains four single-stranded complementary DNA arms that are capable of further linking the generated squares to each another. In the presence of conditions that continue to contain $\mathrm{Ru}(\mathrm{bpy})_{3}{ }^{2+}$, these structures dimerize (Scheme S2ii) and continue to grow in one-dimension into extended periodic DNA ladders (Scheme S2iii).

Scheme 2 Self-assembly of tris branched DNA building blocks 3 and 3 ' in the presence of Ru(bpy ${ }_{3}{ }^{2+}$.

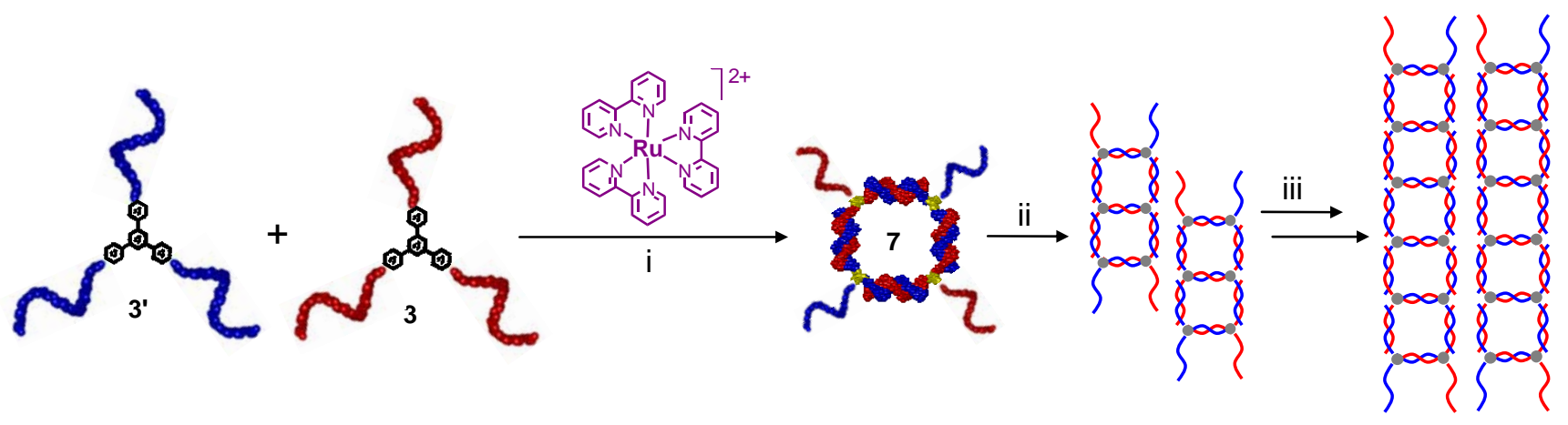

As anticipated, AFM analysis of such extended DNA ladders appears quite different from that of the ill-defined networks generated from the hybridization of just $\mathbf{3}$ to 3 ' without $\mathrm{Ru}(\mathrm{bpy})_{3}{ }^{2+}$. Mostly, highly extended one dimensional DNA filaments of relatively large dimensions are observed thoughout the entire mica surface. Figure S11 exemplifies the typical assemblies generated, which were observed to span tens of $\mu \mathrm{m}$ in length. Unlike the ill-defined networks generated from the assembly of $\mathbf{3}$ and $\mathbf{3}$, these architectures are almost $100 \mathrm{~nm}$ in height (Figure S12). It is of interest to note that the dimensions 

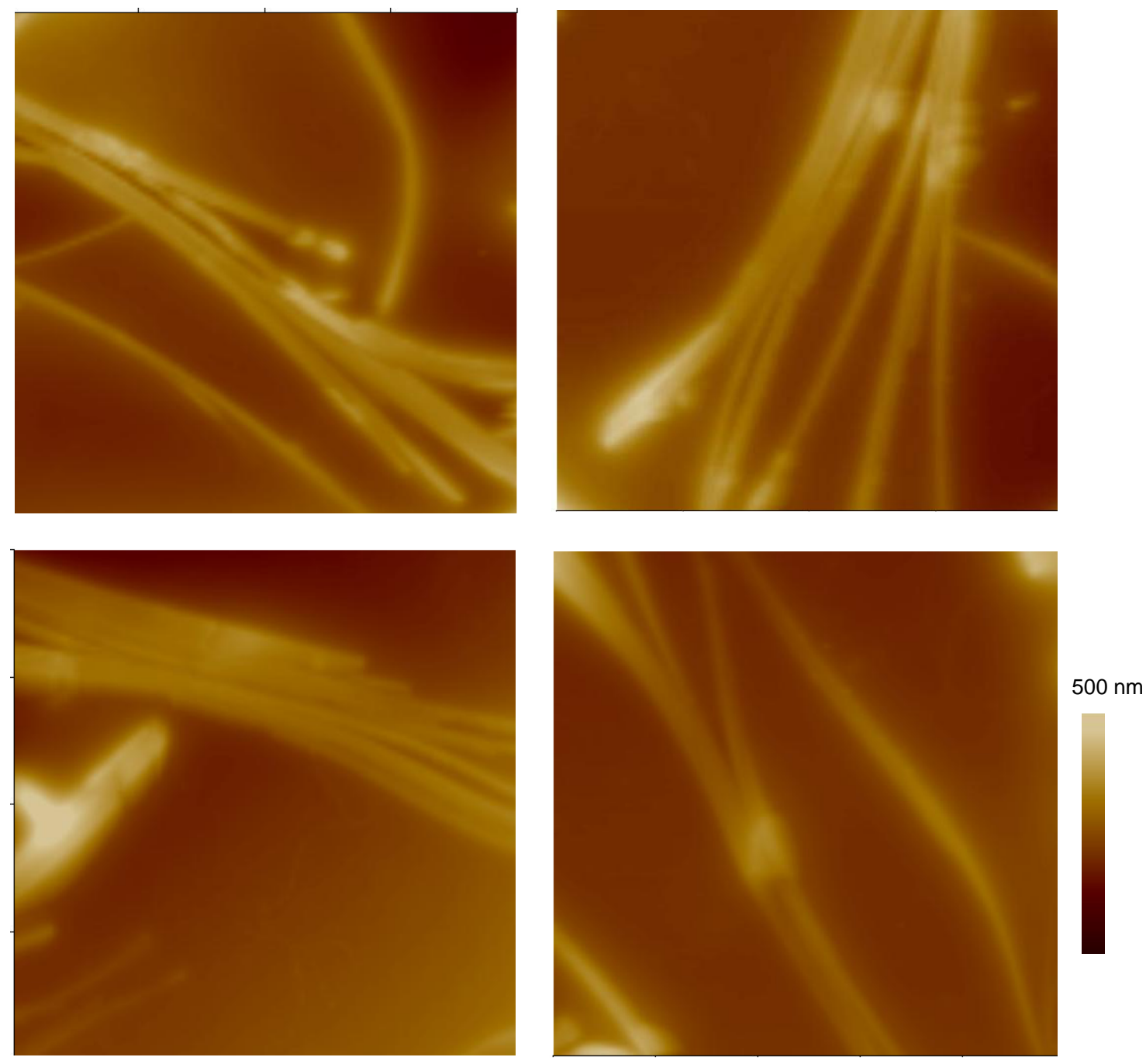

$10 \mu \mathrm{m}$

Figure S11 Analysis of 3 and 3 ' in the presence of Ru(bpy $)_{3}{ }^{2+}$. AFM images of the structures generated from the self-assembly of $\mathbf{3}$ to 3 ', in the presence of $\mathrm{Ru}(\mathrm{bpy})_{3}{ }^{2+}$ reveal the formation of well-defined periodic DNA fibers that extend over tens of $\mu \mathrm{m}$. All images are 10 X $10 \mu \mathrm{m}$.
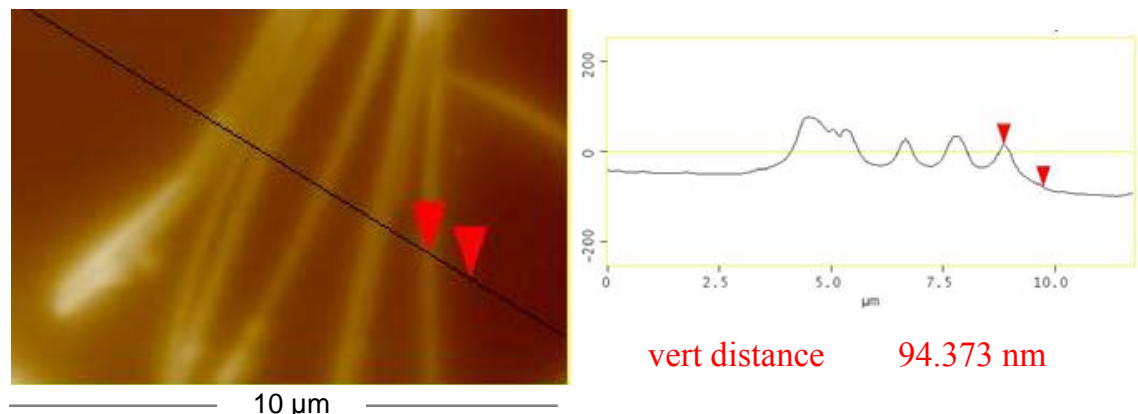

vert distance $\quad 94.373 \mathrm{~nm}$

Figure S12 Cross sectional analysis of the fibers generated from 3 and 3 ' in the presence of $\mathrm{Ru}(\mathrm{bpy})_{3}{ }^{2+}$. 
of a square generated from $\mathbf{3}$ and $\mathbf{3}^{\prime}$ is $\mathrm{nm}$ in length, and that over 1,500 such squares need to periodically assemble in order to generate a DNA filament that is just $20 \mu \mathrm{m}$ long. These filaments appear to result from the inter-wrapping of the one dimensional DNA ladders that are initially generated from the assembly of $\mathbf{3}$ to $\mathbf{3}^{\prime}$ with $\mathrm{Ru}(\mathrm{bpy})_{3}{ }^{2+}$, in a manner quite similar to the wrapping of multiple fibers to generate a rope. Figure S13 contains some of the observed examples in which the larger filaments were found to unravel into the smaller fibers. These fibers appear to have also formed following the wrapping of finer DNA assemblies. Figure S14 contains an AFM image of the smallest structures observed from $\mathbf{3}$ and 3 ', in the presence of $\mathrm{Ru}(\mathrm{bpy})_{3}{ }^{2+}$, which are believed to correspond to the initially generated extended DNA ladders.
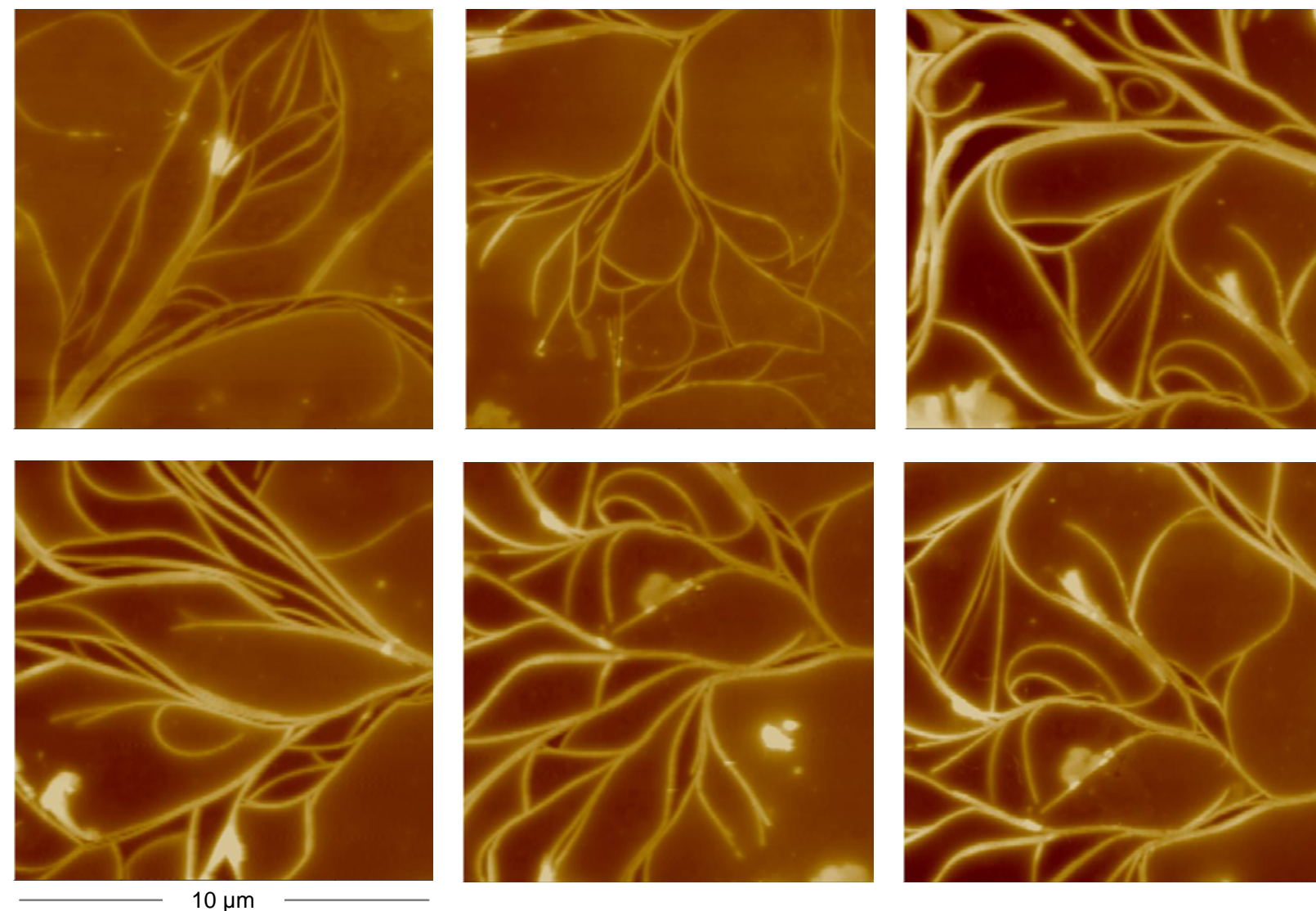

$125 \mathrm{~nm}$

Figure S13 Analysis of the fibers generated from 3 and 3 ' with Ru(bpy $)_{3}{ }^{2+}$. Further analysis of the large fibrous assemblies generated from 3 and 3 ' using $\mathrm{Ru}(\mathrm{bpy})_{3}{ }^{2+}$ were found to form from raveled extended DNA fibers. 

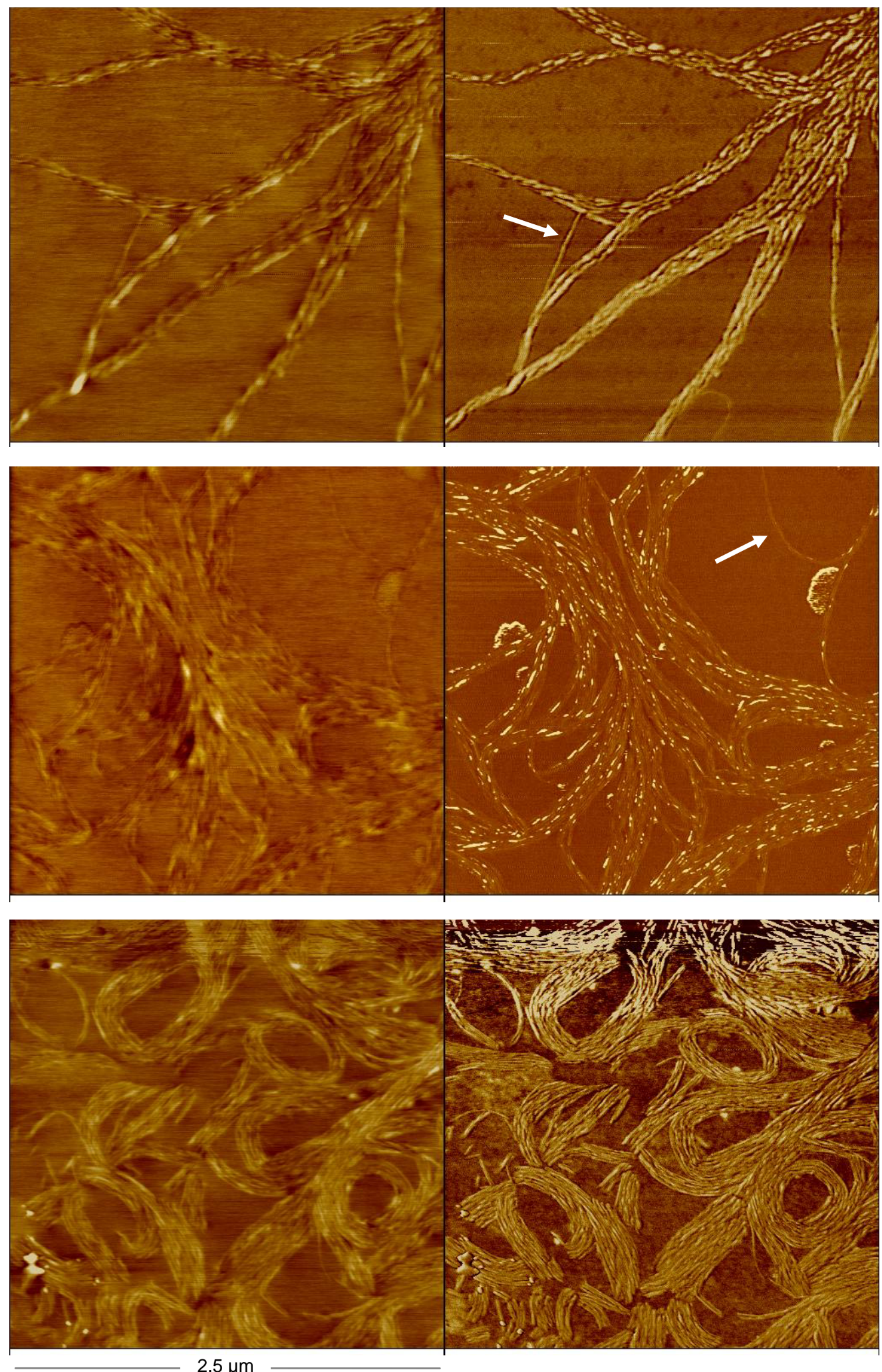

Figure S14 Finest structures observed following the hybridization of 3 and 3 ' with $\mathbf{R u}(\mathbf{b p y})_{3}{ }^{2+}$. In all three examples, the left images correspond to the height, while the right images correspond to their respective phase. All images are 2.5 X $2.5 \mu \mathrm{m}$. 
Cross sectional analysis of these features reveal their height to be around $2 \mathrm{~nm}$ (Figure $\mathrm{S} 15$ ). Furthermore, control experiments were conducted to confirm that these structures were not generated from the simple addition of $\mathrm{Ru}(\mathrm{bpy}){ }_{3}{ }^{2+}$ to either
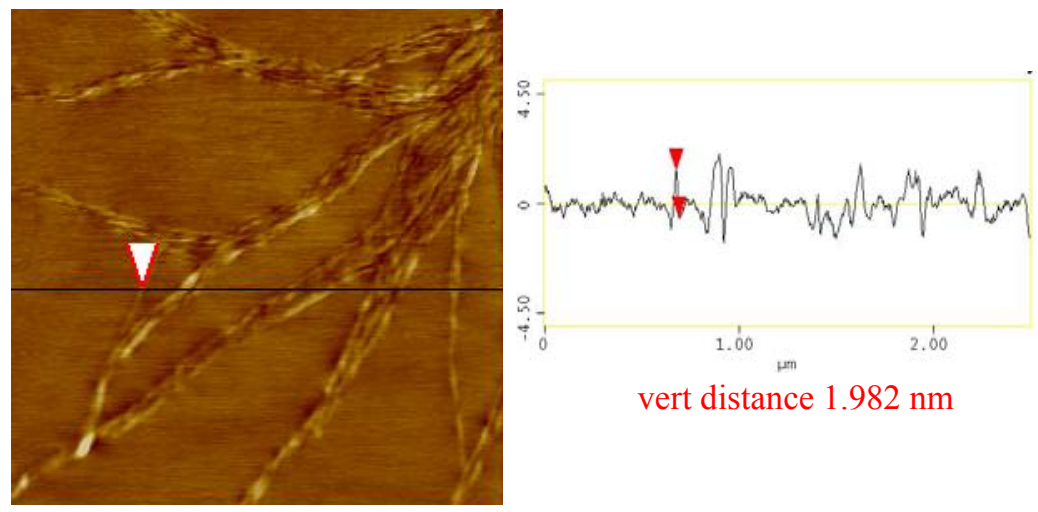

vert distance $1.982 \mathrm{~nm}$

Figure S15 Cross-sectional height analysis. Height analysis of the smallest structures observed showed them to be $2 \mathrm{~nm}$ high, the width double stranded DNA.

of 3 or of 3' individually (Figure S16).

a)

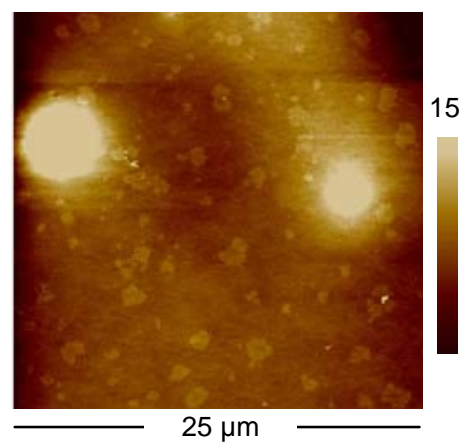

Figure S16 Control experiments on 3 and 3' with

Ru(bpy) ${ }_{3}{ }^{2+}$. No assemblies of any type were observed when either of 3 or 3 are individually analyzed using AFM (panel a and $b$, respectively) b)

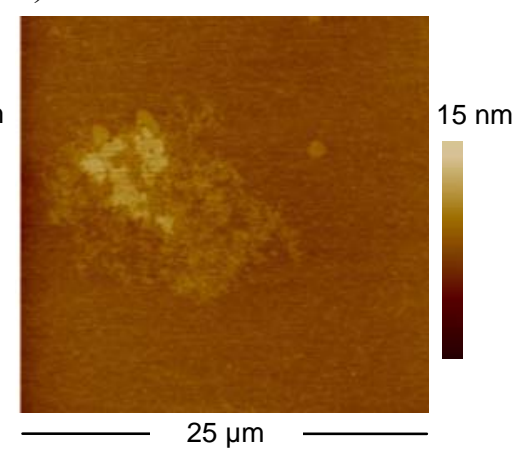
(1) 

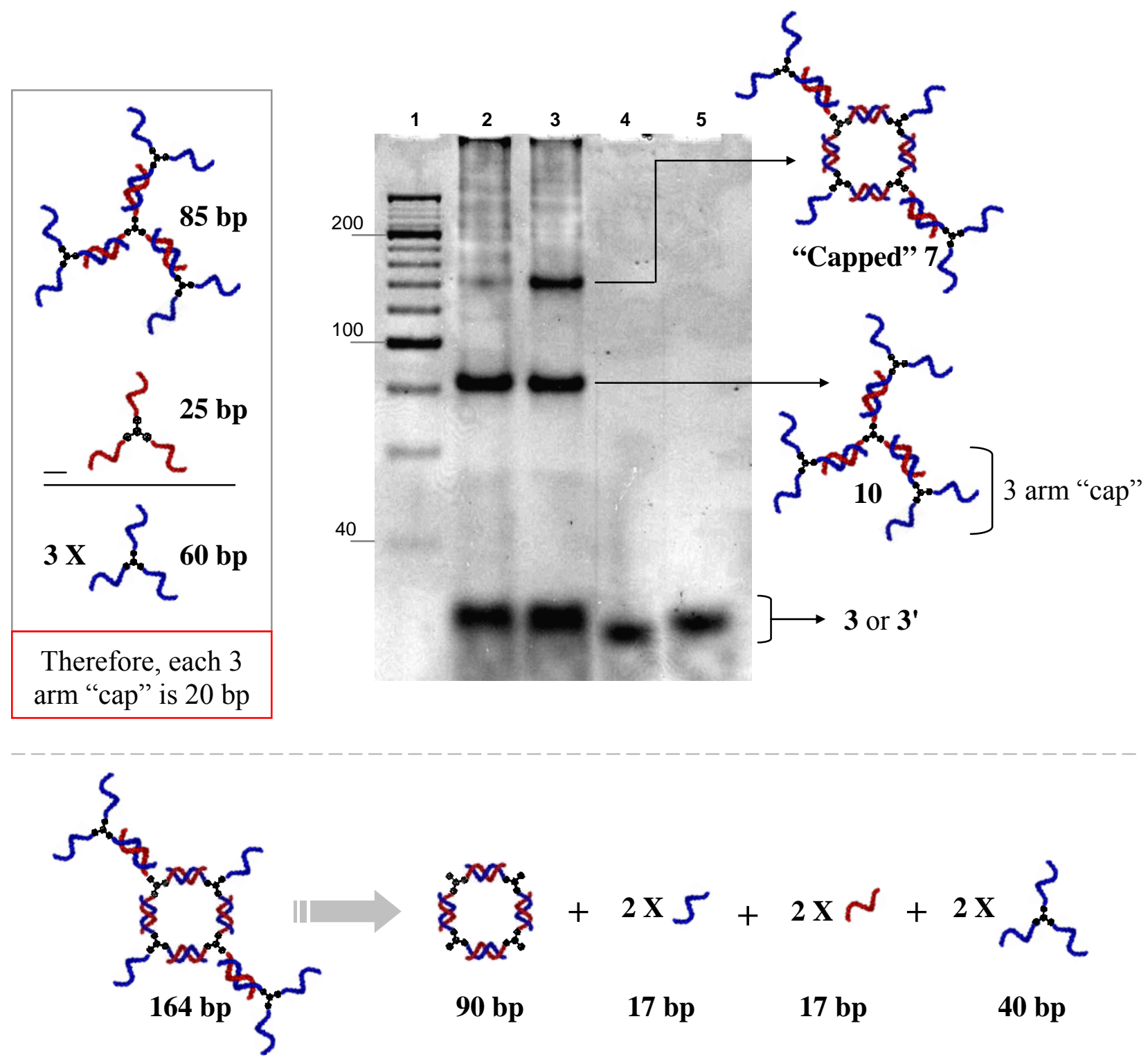

Figure S16 Hybridization of excess 3' to 3. The addition of $\mathbf{3}^{\prime}$ to $\mathbf{3}$ in a 10 fold excess (at $25^{\circ} \mathrm{C}$ ) results in a single discrete product of relatively high electrophoretic mobility that has been assigned to a star-like tetrameric construct in which each DNA arm of 3 is capped with a single unit of 3' (lane 2). The same self-assembly in the presence of the small molecule $\mathrm{Ru}(\mathrm{bpy})_{3}{ }^{2+}$ generates an additional discrete band assigned to a tetrameric square capped with two additional units of 3' (lane 3). Lanes 4 and 5 contains 3 and 3', respectively, while lane 1 contains the 20 base pair linear molecular weight DNA ladder. 
10, made up of a single unit of $\mathbf{3}^{\prime}$ and three units of $\mathbf{3}$, in which each DNA arm of $\mathbf{3}$ ' is capped with a single unit of $\mathbf{3}$. In the presence of $\mathrm{Ru}(\mathrm{bpy})_{3}{ }^{2+}$, hybridization of $\mathbf{3}$ to $\mathbf{3}^{\prime}$ in the same excess of 10:1 was found to generate a second discrete product in addition to $\mathbf{1 0}$ (lane 3). This assembly was found to move as a 150-mer when compared to the linear base pair DNA ladder in lane 1, and was assigned to a tetrameric assembly of four building blocks (i.e. two $\mathbf{3}$ and two $\mathbf{3}^{\prime}$ ) capped with two units of $\mathbf{3}$ (i.e. “capped" 7). As expected, this capped tetrameric assembly is in fact retarded in mobility when compared to tetramer 5. The fact that a single other band is generated in the presence of $\mathrm{Ru}(\mathrm{bpy})_{3}{ }^{2+}$ confirms its role in re-directing the self-assembly of $\mathbf{3}$ to $\mathbf{3}$ ' to generate a single construct (i.e. square 7), in a manner similar to that in which it re-directs the self-assembly of $\mathbf{2}$ and 2 ' to generate a single assembly quantitatively (i.e. square 5).

We have used the gel mobility of this structure, as compared to linear molecular weight markers, as well as internal markers from our own experiments to confirm the characterization of "capped" 7. Square 5 moves on native PAGE as a 90-bp fragment, when compared to the linear base pair marker. "Capped" square 7 is structurally analogous to square 5, with four additional single-stranded 17 -mer DNA arms, as well as two three-arm "caps". We estimate that each three-arm "cap" retards the overall mobility of the assembly by 20-base pairs, as compared to the molecular weight ladder. This is done by comparing the mobility of $\mathbf{1 0}$ with that of $\mathbf{3}$ from the gel in Figure 1. $\mathbf{1 0}$ has a mobility of an 85 base pairs while 3 moves as a 25 -mer, therefore each "cap" is assigned a retardation factor of $(85-25) / 3=20$ base pairs (see Figure 1). Using this estimate, as well as the four additional single stranded DNA arms (34 base pairs in total) we calculate that "capped" square 7 would move as a 164-mer. We find that the mobility of "capped" 7 to indeed be around 150 base pairs. The fact that this capping process generates a single assembly whose mobility matches the estimate of a "capped" square strongly argues in favor of the exclusive formation of square $\mathbf{7}$ from $\mathbf{3}$ and 3', in analogy to $\mathbf{2}$ and 2'. 
The assembly behavior of $\mathbf{3}$ and $\mathbf{3}$ ' in the presence of $\mathrm{Ru}(\mathrm{bpy})_{3}{ }^{2+}$ is thus strongly indicative of one dimensional DNA ladders. This assignment is based on the following observations: (i) the addition of 2 to 2 ' (the two-arm equivalents of $\mathbf{3}$ and $\mathbf{3}^{\prime}$ ) in the presence of the same $\mathrm{Ru}(\mathrm{bpy}) \mathrm{3}_{3}{ }^{2+}$ exclusively generates a single square 5, as unequivocally characterized by gel electrophoresis mobility-shift studies and by MBN enzymatic digestion assays. (ii) the addition of $\mathbf{3}$ to $\mathbf{3}^{\prime}$ in the presence of $\mathrm{Ru}(\mathrm{bpy})_{3}{ }^{2+}$ initially generates a single square 7 , which is a modified analogue of tetramer $\mathbf{5}$, that contains four single stranded DNA arms capable of further assembly. As detailed above, this is confirmed using gel electrophoresis experiments, in which $\mathbf{3}$ is added in a ten-fold molar excess to $\mathbf{3}^{\prime}$ in the presence of $\mathrm{Ru}(\mathrm{bpy})_{3}{ }^{2+}$, to essentially "cap" the square 7 and prevent it from further assembly. Under these conditions, we observe the formation of a single discrete assembly assigned to the "capped" square structure 7. (iii) in the presence of conditions that continue to contain $\mathrm{Ru}(\mathrm{bpy})_{3}{ }^{2+}$, square 7 assembles into one-dimensional DNA fibers $\mathbf{8}$, as characterized by atomic force microscopy studies. Since any other type of assembly using these three armed branched DNA building blocks is expected to result in either two-dimensional or three-dimensional constructs, we believe that the linear fibers observed by atomic force microscopy are strongly consistent with DNA ladders composed of square 7 repeat units.

\section{AFM sample preparation and analysis}

AFM sample preparation generally involves the deposition of $10 \mathrm{uL}$ of the self-assembled mixture (concentration of $10 \mathrm{pM}$ ) onto freshly cleaved mica (dimensions of $2.5 \mathrm{~cm}$ by $2.5 \mathrm{~cm}$ ), followed by adequate evaporation to achieve complete dryness (typically 30 minutes in a fumehood). Whenever possible, imaging is conducted within 24 hours in order to minimize time-dependant sample degradation. 
AFM images were acquired in air and at room temperature using "tapping mode" on a Digital Instruments Dimension 3100 and / or E-scope microscope. "Tapping mode" (i.e. intermittent contact imaging) was performed at a scan rate of $1 \mathrm{~Hz}$ using etched silicon cantilevers with a resonance frequency of $\sim 300 \mathrm{kHz}$, a spring constant of $\sim 42 \mathrm{~N} / \mathrm{m}$, and a tip radius of $<10 \mathrm{~nm}$. All images were acquired with medium tip oscillation damping (20-30\%.)

N.B. $\%$ oscillation damping $=\frac{(\text { free air amplitude }- \text { imaging setpoint amplitude })}{\text { free air amplitude }} \times 100$

\section{References}

S1 References 2a and 2c in manuscript.

S2 Distler, A. M.; Allison, J. Anal. Chem. 2001, 73, 5000-5003.

S3 (a) Kroeker, W. D.; Kowalski, D.; Laskowski, M. Sr. Biochemistry 1976, 15, 4463-4467. (b)

Johnson, P. H.; \& Laskowski M. Sr. J. Biol. Chem. 1970, 245, 891-898. 